\title{
Flensborgs guldsmede
}

\author{
En forstudie
}

\author{
Af Sigurd Schoubye.
}

Ejendommeligt nok foreligger der ingen publikationer om guldsmedehåndværket $\mathrm{i}$ Flensborg, og oplysninger vedrørende byens guldsmede har til nu været begrænset til et i Flensborg Museum samlet kartotek med henved 85 navne, som delvis er anvendt $i$ inventarværket Die Kunstdenkmäler des Landes Schleswig-Holstein. Tilsvarende er guldsmedehåndværket i Slesvig og Eckernførde samt i de østligt beliggende byer i Holsten (med undtagelse af Kiel') så godt som ubehandlet, hvorved det er overmåde vanskeligt at identificere de $i$ dette håndværksmæssigt og kunstindustrielt betydningsfulde område udførte guldsmedearbejder.

I modsæining hertil er de nordslesvigske byer og vestkystbyerne i Sydslesvig og Holsten så grundigt udforskede at vi har en nogenlunde sikker forestilling om det derværende guldsmedehåndværks karakter og særpræg', ligesom omfattende mesterlister for de egentlige guldsmedecentrer, Hamborg, Lübeck og København, gor det muligt at bestemme arbejder herfra."

For at råde bod på denne besværlige brist forelægges hermed en orienterende liste over guldsmede i Flensborg fra tiden mellem 1500 og 1900, idet tilføjes at den ikke alene er ufuldstændig, fordi lakuner $i$ arkivstoffet (en meget ufuldstændig borgerbog og mangel på akter fra byens guldsmedelav) udelukker en blot nogenlunde komplet fortegnelse, men også i visse henseender for omfattende, fordi mange af de anførte guldsmede - omend i kilderne benævnte som sådan - ikke har været selvstændige mestre og altså næppe efterladt sig arbejder at identificere, eller - for middelalderens vedkommende - måske blot har haft ordet guldsmed som efternavn. Men bortset fra nogle ganske enkelte stempler har de $\mathbf{i}$ offentlig eje foreliggende sølvgenstande kunnet 
bestemmes, så først en eftersøgning af eventuelt Flensborg-sølv i privateje ud fra samme principper som Tønder-guldsmedene er udforsket efter, vil kunne tilvejebringe de mange manglende mesterstempler. Da en sådan undersøgelse er en overordentlig omstændelig og tidkrævende sag, og da resultatet heraf vil blive for omfattende for en årbogsafhandling, vil en sammenfatning af det nærmest foreliggende materiale formentlig være til nytte og anvendelig for videre udforskning af de mange anonyme sølvgenstande i landsdelen.

Det er indlysende, at Flensborg som rigets næststørste by må have haft en betydelig guldsmedetradition. Det fremgår alene af to betydelige dokumenter som skråen for malerne, guldsmedene, glarmestrene og snedkerne i Flensborg fra $1497^{4}$ og den såkaldte Flensborger-konstitution fra 1646 . $^{5}$ Den forstnæunte er ved siden af den københavnske den eneste bevarede danske guldsmedeskrå fra middelalderen med oplysninger om kravene for mesterprøven, den anden den eneste for hertugdømmerne kendte fællesforordning for lødighedskravene. - At her er tale om et fælleslav tyder på at antallet af guldsmede ikke har været stort nok til at man har kunnet danne et selvstændigt, men 100 år senere skilte guldsmedene og malerne sig ud fra de andre to til et samarbejde som muligvis har varet til 1615, da Christian den Fjerde for en kort tid ophævede lavsordningen. Da samtlige byens guldsmede ved Flensborger-konsitutionens ikrafttræden kaldtes op på rådhuset og fik pålagt fremtidigt at stemple deres arbejder med et $F$, må man antage, at de har haft deres eget lav, om hvis skæbne vi intet ved. En række for alle guldsmedelav karakteristiske forhold lader sig imidlertid udlede af fortegnelsen, således at rekruteringen i overvejende grad er hjemlig, hovedparten af Flensborgs guldsmede er fra byen og det nærmeste opland og de øvrige overvejende fra hertugdømmerne eller Danmark:

Ảbenrå: nr. 85.

Haderslev: nr. 79, 88, 100, 111, 129 .

Tonder: nr. 96, 119, 134, 156.

Sønderborg: nr. 68, 73, 155.

Logumkloster: nr. 108.

Højer: nr. 157.

Augustenborg: nr. 154.

Frederiksstad: nr. 74 . 


\section{Rendsborg: nr. 69. \\ Kolding: nr. 103. \\ Fredericia: nr. 86. \\ Randers: nr. 153. \\ Ålborg: nr. 132. \\ Vordingborg: $\mathrm{nr} .99$. \\ Nakskov: nr. 92. \\ Buxtehude: nr. 151,}

idet må tilføjes at det ikke altid drejer sig om herkomststedet. Om de ældre guldsmedes tilhørsforhold vides intet.

Ydermere falder det $\mathrm{i} ø j n e n e$, hvor nær beslægtede guldsmedene er. Dette kan konstateres allerede fra middelalderen. Sønnerne bliver guldsmede, døtrene gifter sig med guldsmede, guldsmedeenker gifter sig igen med guldsmede. Sådanne sammenhænge ses f. eks. i forbindelse med: (23-27), (28-36-38-39), (41-44), (43-56), (61-66-67-72), (68-74-80-104-98-106-110), (79-96-105), (75-81), (76-78-83-97-109), (101-120-147-113-136-138) og (112-137-145131-162).

Om de overleverede arbejder kan oplyses at de fortrinsvis omfatter kirke- og lavssølv. Anselige korpusarbejder dokumenterer kvaliteten. Bordsølvet (bestik) gør sig mindre mærkbart, og dragtsølvet (herunder hovedvandsæg og salmebogsbeslag), som er så betydningsfuldt på vestkysten, er et tilsyneladende svagt område, men hertil må føjes at det netop er de to sidste grupper, man kan forvente at træffe i privateje, og at der således kan komme meget ukendt for dagen ved systematisk efterforskning.

I øvrigt ligger det uden for nærværende afhandlings rammer at give en kunstnerisk og håndværksmæssig vurdering af Flensborgs guldsmedehåndværk.

Kirkesølv træffer vi i Flensborgs 4 kirker og fra Franciskanerklostret, (ca. 20 signerede), i Flensborg amt, (ca. 30 signerede), i Slesvig, Husum og Sydtønder amter, (ca. 12 signerede), samt i Nordslesvig (henved 25 stemplede arbejder).

Det ældste stemplede arbejde er Baltzer Wegeners kalk i Steinberg fra 1569 , måske det ældste overhovedet i dansk guldsmedekunst! Det ældste, men ustemplede, er alterkalken og disken i Helligånds kirken, fra slutningen af 1300 -tallet, men i ovrigt er det gået slemt ud over det gotiske sølv. Kun Steinberg og Valsbøl har bevaret deres middelalderkalke. Kalken fra Kværn befinder 
sig med en sjælden monstrans fra Esgrus i Landesmuseum. Men af de mange sengotiske kalke nord for grænsen kan flere antages at være gjort i Flensborg. Fra perioden 1650-1750, hvor nadverkander og oblatæsker kommer til, er byen derimod som det vil ses i mesterfortegnelsen rigt reprasenteret.

Lavssølvet, der med få undtagelser er samlet i Flensborg Misseum, tildels endnu i dets oprindelige besiddelse, omfatter af stemplet Flensborg-sølv 5 velkomster (bagerne, slagterne, smedene, skrædderne og bødkerne), henved 14 drikkebægre (bagerne, rebslagerne, slagterne), 1 skafferhammer (slagterne), 3 lågkrus og 1 skafferhammer (skipperlavet), og gildesølvet 2 velkomster (S. Nicolai og S. Johs. skyttegilde), 6 bægre (3 hvert sted) og 1 skafferhammer (S. Johs.), samt de til velkomsterne hørende skjolde, der også for en stor del er lokale arbejder.

Interessantest er uden tvivl de fire horn, hvoraf de to har tilhørt kalentet el. Trefoldighedsgildet. Det fjerde, som formodes at have tilhørt de 4 forenede lav, gik siden over i snedkerlavets eje (Museum für Kunst u. Gewerbe 1898. 104) og blev 1656 forsynet med et låg af Hans Buros. ${ }^{6}$ De to første nu kaldet det store og det lille kalentehorn (FM 7667 og 7674) er skænket af biskop Eskil i Ribe o. 1400 og af Nicolaus Hakstede, medl. af kalentet 1505. Fig. 10-11. Det tredje, også kaldet »det sorte (NM 2, D. 7), stammer fra Helligåndsklostret. ${ }^{8}$

I Trefoldighedsgildets gavefortegnelse nævnes $\mathbf{i}$ øvrigt et tredje horn' sammen med et par kalke og 12 skeer.

Mens altså lavs- og kirkesølvet giver et ret fyldigt udtryk for Flensborg-guldsmedenes formåen $i$ tiden fra middelalder til barok, er rokoko, Louis XVI og empire stærkt underrepræsenteret, men der skulle være mulighed for at tilvejebringe genstande fra disse perioder.

\section{NOTER}

1. Franz Gundlach: Kieler Goldschmide vom 14. Jahrhundert bis 1867 (Schl.-Holst. Jahrbuch 1920, Harry Schmidt (ibid. 1943).

2. Bøje, St., SS.

3. K. Hüseler: Meisterliste der Hamburger Goldschmiede v. 14.-18. Jh. Nordelbingen 1950. J. Warncke: Die Edelschmiedekunst in Lübeck und ihre Meister. 1927. Bøje.

4. N. II 273-82, S. I 711-17, Wedel 125-33.

5. SS $56 \mathrm{f}$.

6. KSF 340 . 
7. N. I 269 (Item dominis Eskillus episcopus Ripensis legauit vnum cornu circumdatum argenta) og 294.

8. Olrik 25 f. (fig. 23), N. I 274 (Item in domo conuiuii recepit vnum cornu nigrum circumdatum argento). Da hornet har forgyldte malmbeslag er det tvivlsomt med Schröder (i Festschrift Kunstgewerbemuseum Flensburg) at antage at dette har tilhort kalentet (jvf. Wedel 74).

9. N. I 275 (Item j horn myt suluer belecht).

\section{LITTERATURHENVISNINGER}

Bøje 2 = Chr. A. Bøje: Danske Guld- og Sølvsmedemærker før 1870. Politikens udg. 1954.

DK = DANMARKS KIRKER. Sonderjylland ved Erik Moltke, Elna Møller og Vibeke Michelsen. 1954-64.

DIE KUNSTDENKMALLER DES LANDES SCHLESWIGHOLSTEIN:

KKH $=$ Kreis Husum. 1939.

KKS $=$ Kreis Südtondern. 1939.

KLS = Landkreis Flensburg. 1952.

KSF $\quad=$ Stadt Flensburg. 1955.

KLS = Landkreis Schleswig. 1957.

N I og II $=C$. Nyrop: Danmarks Gilde- og Lavsskråer fra Middelalderen. 1895-1904.

J. Olrik: Drikkehorn og Solvtoj fra Middelalderen til Renæssancen. 1909.

R. $\quad=$ Johannes Reinhusen: Annales Flensburgenses 1558-1604. Quellen und Forschungen zur Familiengeschichte Schleswig Holsteins. I. Kiel 1926.

Peter Rivesell: Versuch einer Beschreibung der Stadt Flensburg. I. Altona 1817.

SS $\quad=$ Sig. Schoubye: Guldsmede-håndværket i Tonder og på Tønder-egnen. 1961.

Sig. Schoubye: Om lødighed og stempling i sonderjysk sølv. Arv og Eje 1958.

S. $\quad$ H. C. P. Sejdelin: Diplomatarium Flensborgense 1865. 73.

St. $\quad=H$. Stierling: Goldschmiedezeichen von Altona bis Tondern. 1955.

J. Warncke: Die Edelschmiedekunst in Lübeck 1927.

$F$. Wedel: Gilder og Laug i Flensborg. 1873.

\section{ARKIVALIEHENVISNINGER}

Foruden Flensborgs meget omfattende kirkebogsmateriale, som er samlet i S. Mariekirkens arkiv, er fra byarkivet - forkortet St. Fl. bl. a. følgende arkivalier anvendt:

Acta betreffend Goldschmiede 1757-1860. St. FI. Nr. 373. Flensburgensien. Von Goldschmieden u. Uhrmachern. Nachrichten ex Protocolles. St. Fl. Nr. 971. 1.

Fo. $\quad=$ Kopfzahl aller Einwohner in der Stadt Flensburg 5. Aug. 1769. 
Fo. $\quad=$ Volkszahl Register der Stadt Flensburg vom 13ten Februar 1803.

Fo. $\quad=$ Volkszählungsregister der Stadt Flensburg vom 1 ten Februar 1835.

Neubürgerlisten 1558-1767. Ved Dr. O. Schütt.

Neubürgerkartei 1845-1866. Ved Dr. O. Schütt.

Geburtsbriefe 1574-1669. Ved Dr. O. Schütt.

Der Stadt Flensburg Schötebuch 1518-1783 v. O. H. Moller.

Der Stadt Flensburg Schötebuch 1784-1791 v. Thor Straten.

$\mathrm{BB}=$ Bürgerbuch.

KGP $=$ Kämmereigerichtsprotokolle.

Sch. $\quad=$ Schötebuch.

RP $\quad=$ Retsprotokoller.

Kr. $\quad=$ Kämmereirechnungen.

Sk. $\quad=$ Stadtrechnungen. St. Fl. $210 \mathrm{ff}$.

\section{MUSEUMSHENVISNINGER}

FM = Flensborg Museum.

LM = Schleswig-Holsteinisches Landesmuseum.

NM $=$ Nationalmuseet.

\section{ØVRIGE FORKORTELSER}

Fl $\quad=$ Flensborg.

B.: Tidspunkt for borgerskab.

Sl $\quad=$ Slesvig.

$\mathrm{Hu}=$ Husum

D.: Dod el. begravet.

ST $\quad=$ Sydtønder.

$\mathrm{Ha} \quad=$ Haderslev.

G.: Gift.

Sø $\quad=$ Sønderborg.

Tø $=$ Tønder.

$\AA \quad=$ Ảbenrå. 


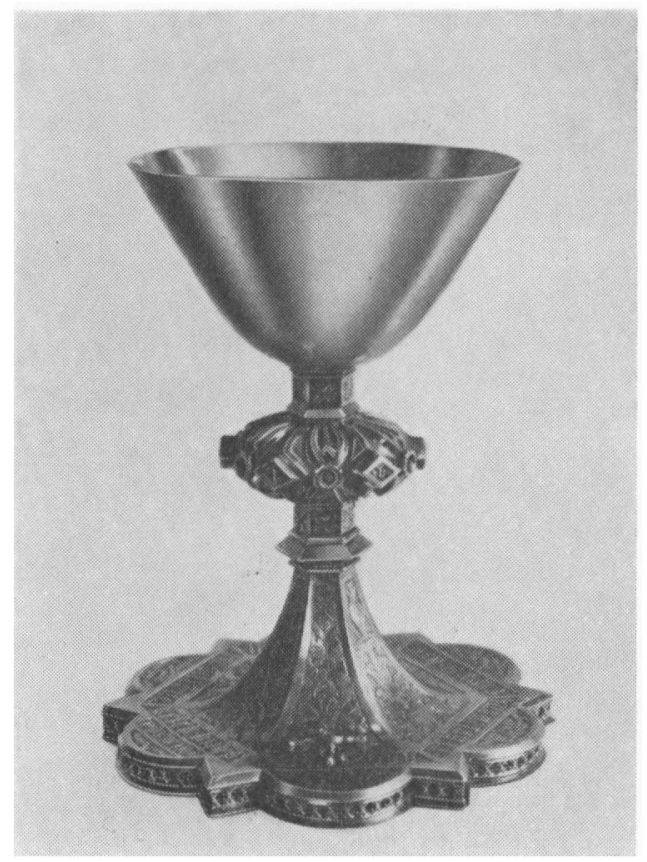

Fig. 1. Gotisk kalk fra Mariekirken i Flensborg. Ca. $1400.20 \mathrm{~cm} \mathrm{h.} \mathrm{Sekstunget} \mathrm{fod} \mathrm{med} \mathrm{spidser.}$ Korsblomster i standkanten. Jvf. S. Nicolai / A (DK 1695 f), Stepping (DK 338) og Valsbel (KLF 362). På foden graveret frakturinscription i omlobende sekskant: biss chop / eckel van / ripen hev / $t$ ghe ghev / en dissen / kelck bidet / vor sin s(eele). - Der må være tale om den samme biskop Eskil, død 1409, som forærede kalentet det store horn (jvf. fig. 10). - På foden støbt krucifiks. Fodtragten har i de seks felter forskelligt graveret bladværk. Sekskant. knop med j h e c v s i frakturskrift. Til kalken har hørt disk og oblatæske.

Fot. Flensborg Museum.

Om Mariekirkens middelalderlige solv oplyses, at man 1562 solgte een stor monstrans, andre monstranser, tre kalke, pretiosa, klenodier i form af sølvampuller og relikvier. (KSF 123). 


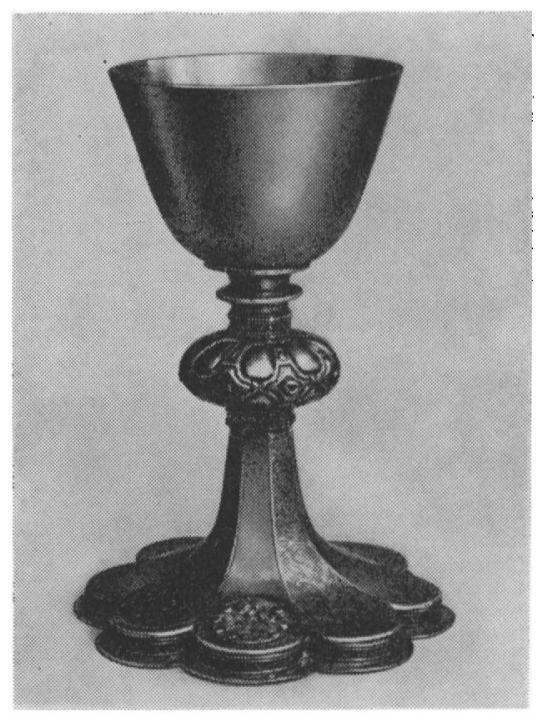

Fig. 2. Helforgyldt kalk fra Steinberg k. 1569, udført af Baltzer Wegener (nr. 36). $18 \mathrm{~cm} \mathrm{h.} \mathrm{Otte-tunget} \mathrm{fod} \mathrm{med}$ liggende s-buer i standkanten. Felterne skiftevis glatte og graverede med rankeværk i Flötnerstil. Inscr. i randen: DEN 26 IVNY ANNO 1569 HEFT DE ERBAR VND ERENFESTER ELER PETERSEN ERFGESETEN THO

NORGARDEN DISEN KELCK DER KARCKN STENBARG IN DE ERE GADES VOR SICK VND SINE ARVEN GEGEVEN.

Giverens våben $i$ medaljon, omgivet af røde og gronne sten, $i$ en af tungerne f. n. Fladoval knop med tunger, påsat ædelstene. Her er tale om det ældste danske guldsmedearbejde med identificeret mestermærke. (KLF 344).

Fot. Landesamt für Denkmalpflege. 


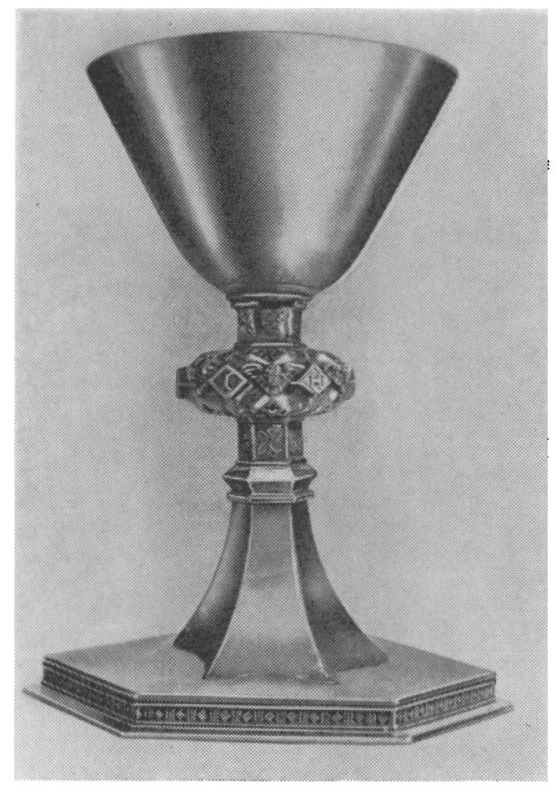

Fig. 3. Kalk fra Ullerup k., fmtl. fra 1618 og af Peter Buros (nr. 61). Dog ustemplet. Iflg. kirkeregnskabsbogen leverede han d. a. kalk og disk for 51 mark og 9 skilling $i$ arbejdslon og $48 \mathrm{mk}$., $15 \mathrm{sk}$. og 9 p. for $41^{1 / 4}$ lod solv. Kalken, der tilsyneladende er gjort efter en ældre sengotisk i samme kirke (DK 2255, fig. 7), har sekskantet fod med rudemonster i standkanten. I skaftleddene graverede firblade, og den ovale knop har mellem rudebosserne med reliefversalerne ihesvs påloddede, støbte keruber. Bægeret menes samtidigt.

Fot. Danmarks Kirker. 


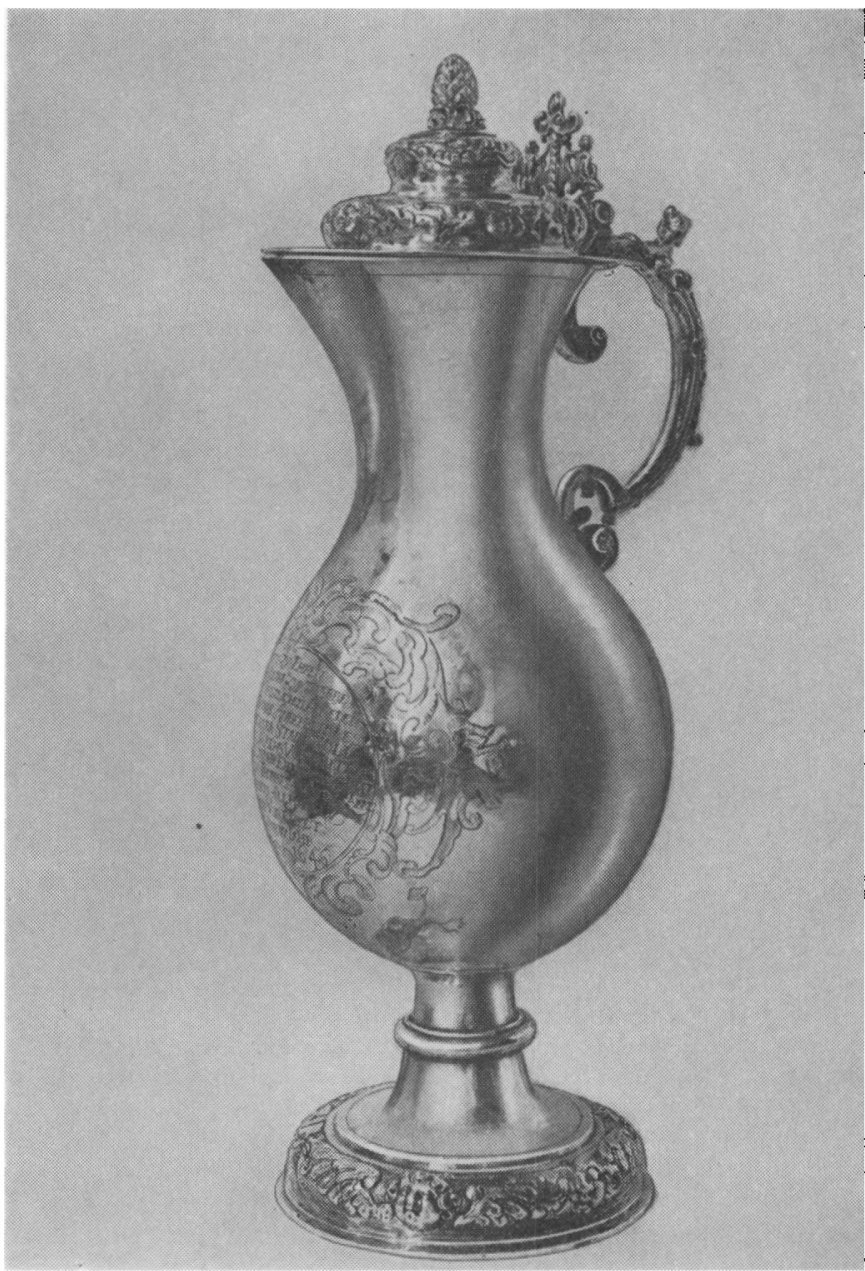

Fig. 4. Alterkande fra Tonder k. 1646, udført af Evert Buros (nr. 67). $40.5 \mathrm{~cm} \mathrm{~h}$. I stil som Mariekirkens kande fra 1643 af Carsten Mundt, Hamborg (KSF $125 \mathrm{f}$ ). Rund fod med rundstavsprofil, hvorpå drevne englehoveder. Låget med dobbelt rundstav og afsluttet med pinje. Stabt hank med fremspringende hoved og - som Hamborgkanden - med to modvendte C-bøjler. Flad støbt gæk, akantusblad omgivet af siddende par. Stærkt buget korpus med kraftig tud. Under denne rigt graveret oval i kartoucheramme med giverindskriften: GOTT ZU EHREN DEM ALTAR ZUR ZIERDE UND ZUM CHRISTLICHEN ANGEDENCK HERREN THOMAS ANDERSEN DES ELTEREN DIESER STADT WOLLVORDIENTEN RATHS VORWANTEN IHRES SELL, LIEBEN EHEMAN. NES HAT HELLLWICH THOMSES DIESE KANNE DER KIRCHEN ALLHIR ZU TUNDERN VOREHRET AUFF NEW IAHR ANNO 1646.

Fot. Danmarks Kirker. 


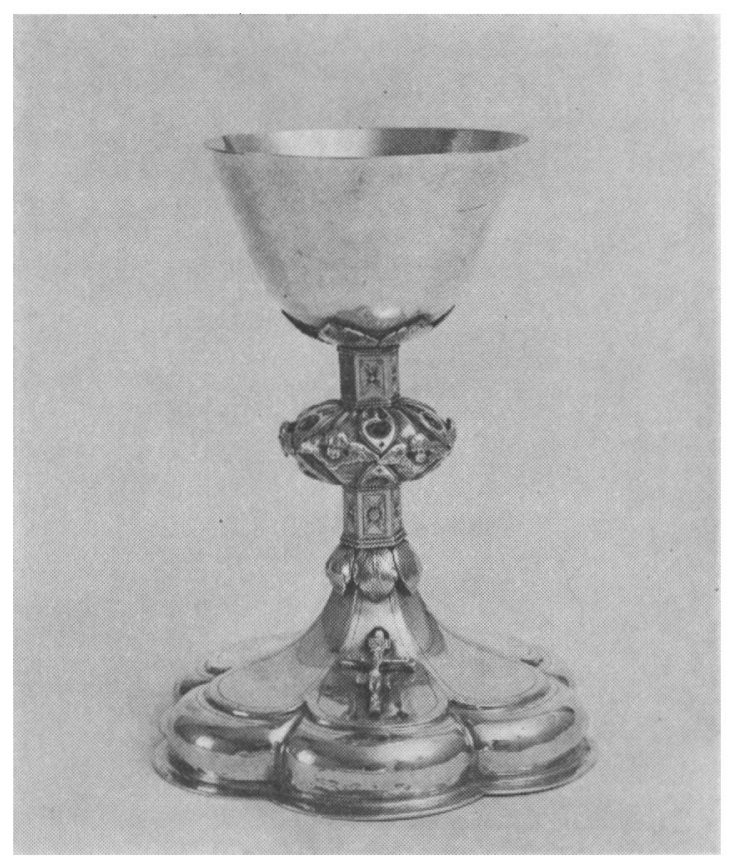

Fig. 5. Kalk fra Sottrup k. 1665, delvis udfert af Heinrich Matthiessen (nr. 68). Knoppen og skaftleddene er fra 1500-tallet, medens den sekstungede fod med vulst samt påloddet stobt krucifiks, helt i tidens stil, må være fra Matthiessens værksted. Det nævnte år fär han 103 mk. og 2 sk. for en kalk (DK 2236). Bægeret formentlig også af M., selv om det efter formen skulle være aldre.

Fot. Danmarks Kirker.

Figur 6. Oblatæske fra Asbøl k. 1700., udfort af Hinrich Block (nr. 74). $4 \mathrm{~cm} \mathrm{h.,} 6.6 \mathrm{~cm}$ i tvm. Glat. På det svagt hvælvede låg giverinscriptionen: GOTT ZU EHREN DEM ALTAR ZUR ZIERDE VEREHRET HANS MARTEN KNESPEL DER KIRCHEN ZUR ATZB''L Ao 1700 d. 3. Octob. (DK 1912).

Fot. Danmarks Kirker.

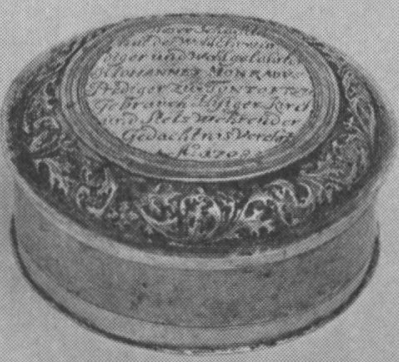




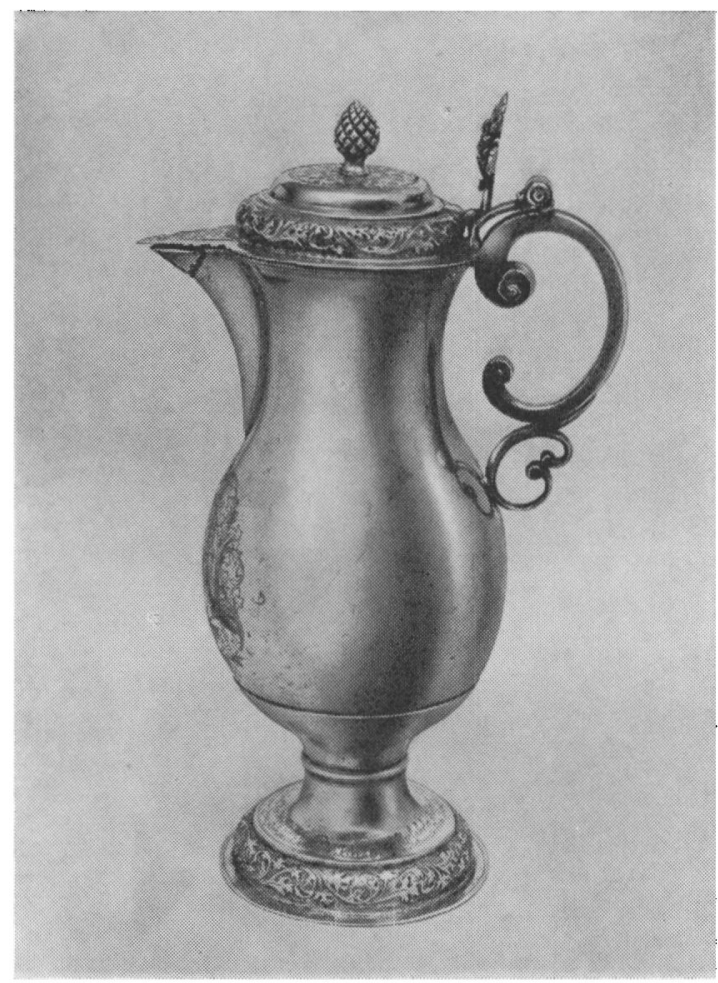

Fig. 7. Alterkande fra Nordborg k. 1708, udfart af Hinrich Block (nr. 74). $33 \mathrm{~cm}$ h. Rund fod med rundstavsprofil med dreven akantusranke som går igen på lågets tilsvarende profil (og på en tilhørende oblatæske) og cirkelfelt. Stabt flad gak med drueklase og blade. Stobt håndtag med modvendte C-bøjler. Korpus - i overensstemmelse med tiden - mindre buget end de forste nadverkander. Under tuden i oval i stedet for giverinscription en overmåde sjælden graveret nadverscene. På foden $i$ kursiv: Diese Kan hat H. Iohannes Monradus Verehret Ao. 1708. (DK 2184). Fot. Danmarks Kirker. 


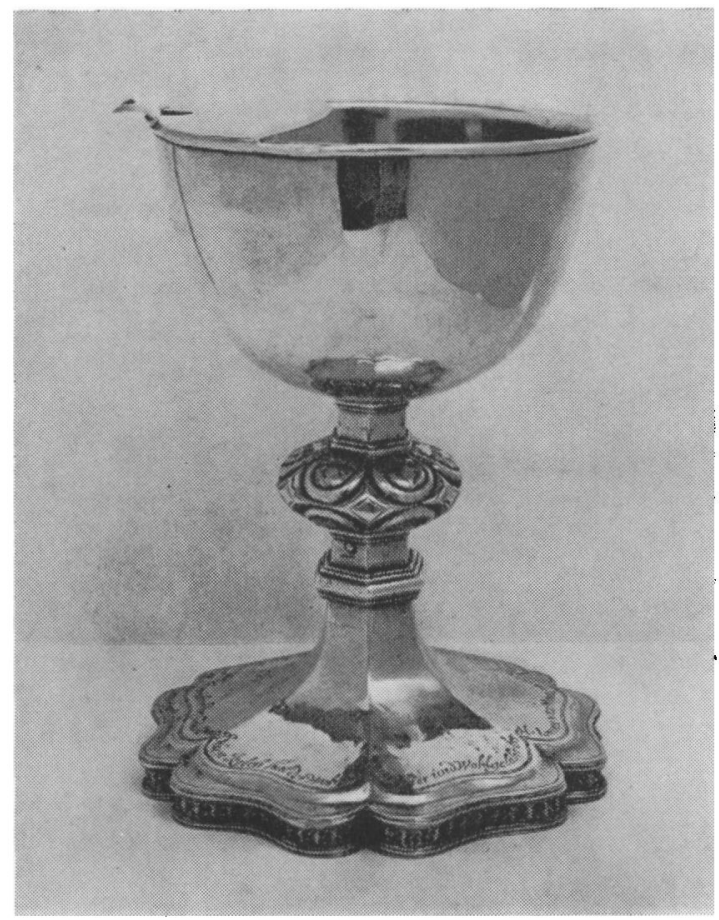

Fig. 8. Alterkalk fra Nordborg k. 1708, udført af Hinrich Block (nr. 74). $22 \mathrm{~cm} \mathrm{~h}$. Sekstunget, accoladeformet fod med standkant $\mathrm{i}$ gotiserende maner (svarende til kalken i S. Marie, KSF 125). Indscr. i kursiv langs kanten: Diesen Kelch hat der wohl Ehrwürdiger und Wohlgelahrter H. Iohannes Monradus Predigr zu Tontoft zum Gebrauch Hisiger Kirchen und Stetswahrenden Gedähtnis Verehret 1708. - Sekskantede skaftled og oval knop med tunger. Senere bæger. (DK 2184).

Fot. Danmarks Kirker. 


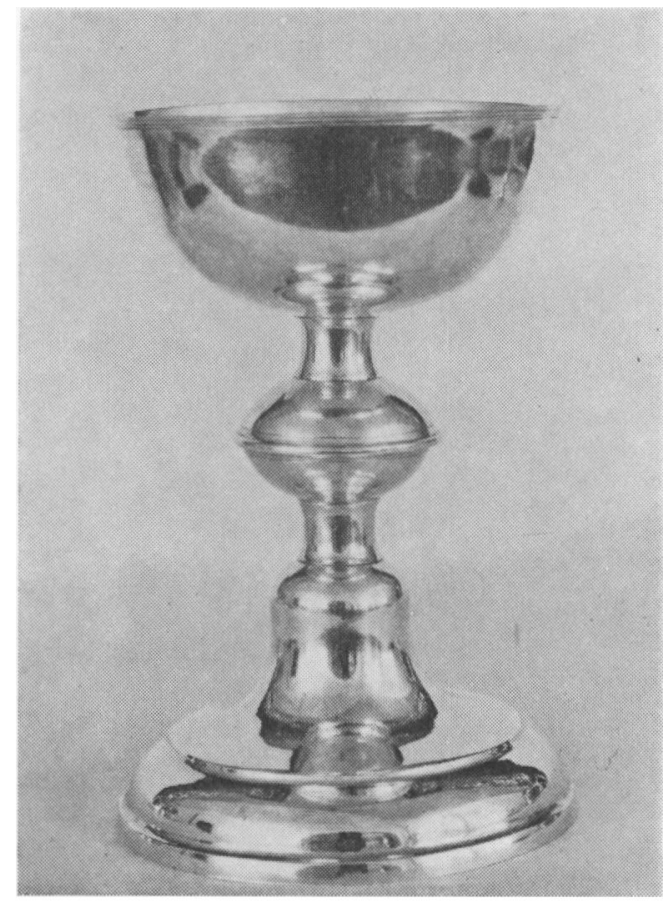

Fig. 9. Alterkalk fra Bov k. 1796, udført af Hans Thun (nr. 105). $21.5 \mathrm{~cm}$ h. En enkel, noget fantasilos form, cirkulær fod med fladt rundled, klokkeformet skaft og spidsoval midtdelt knop. Eksempel på hvor vanskeligt det faldt guldsmedene at forny kirkeselvet. Inscr.: Durch die Freiwilligen Beiträge Fast Aller in diesen Gemeine ist dieser Kelch, nebst der Scharhtel im Jahr 1796 verfertiget - 37 Loht. (DK 2033)

Fot. Danmarks Kirker. 


\section{FLENSBORGS GULDSMEDE}

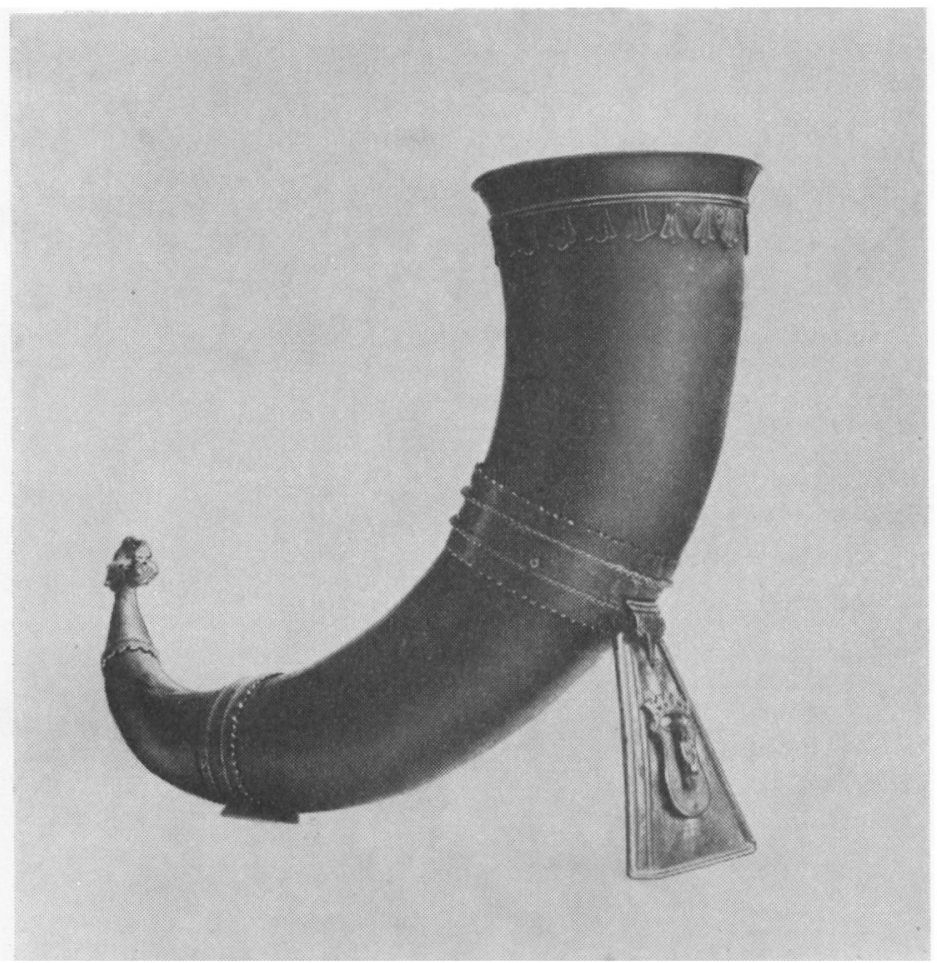

Fig. 10. Det store kalentehorn. 0. 1400. (FM 7667). $28 \mathrm{~cm} \mathrm{h.,} 44 \mathrm{~cm}$ br., diam. ved munding $11.5 \mathrm{~cm}$. (Jvf. indledningen. Olrik mener i ovrigt ikke, at dette horn er identisk med biskop Eskilds). Beslagene er af sølv, og ornamenteringen peger mod nordisk oprindelse. Inscr.: dit horn hort in den kalant to flensborch (fraktur).

Fot. Flensborg Museum.

Fig. 11. Det lille kalentehorn. 0. 1490. (FM 7674). $17.8 \mathrm{~cm} \mathrm{h.,} 24.7 \mathrm{~cm} \mathrm{br.,}$ diam. ved munding $8.8 \mathrm{~cm}$. Her er kun een midterring, også af sølv, til hvilken er påloddet to kløer med hver fire tæer. $P a ̊$ ringen indskriften: help god unde ma(ria). Mundingen tragtformet, prydet med akantusranker og kalentets sindbillede, den lidende Kristus. Nederst en tovsnoning. På hornets spids en rorformet afslutning med en knop af tre blade. Givernavnet $h$ nicolaus hakstede i minuskler på drikkerandens forside. Fot. Flensborg Museum.

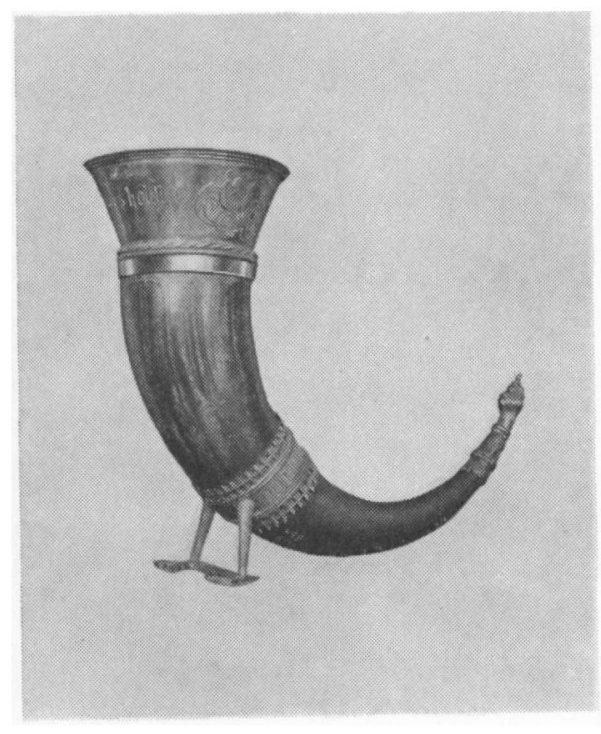




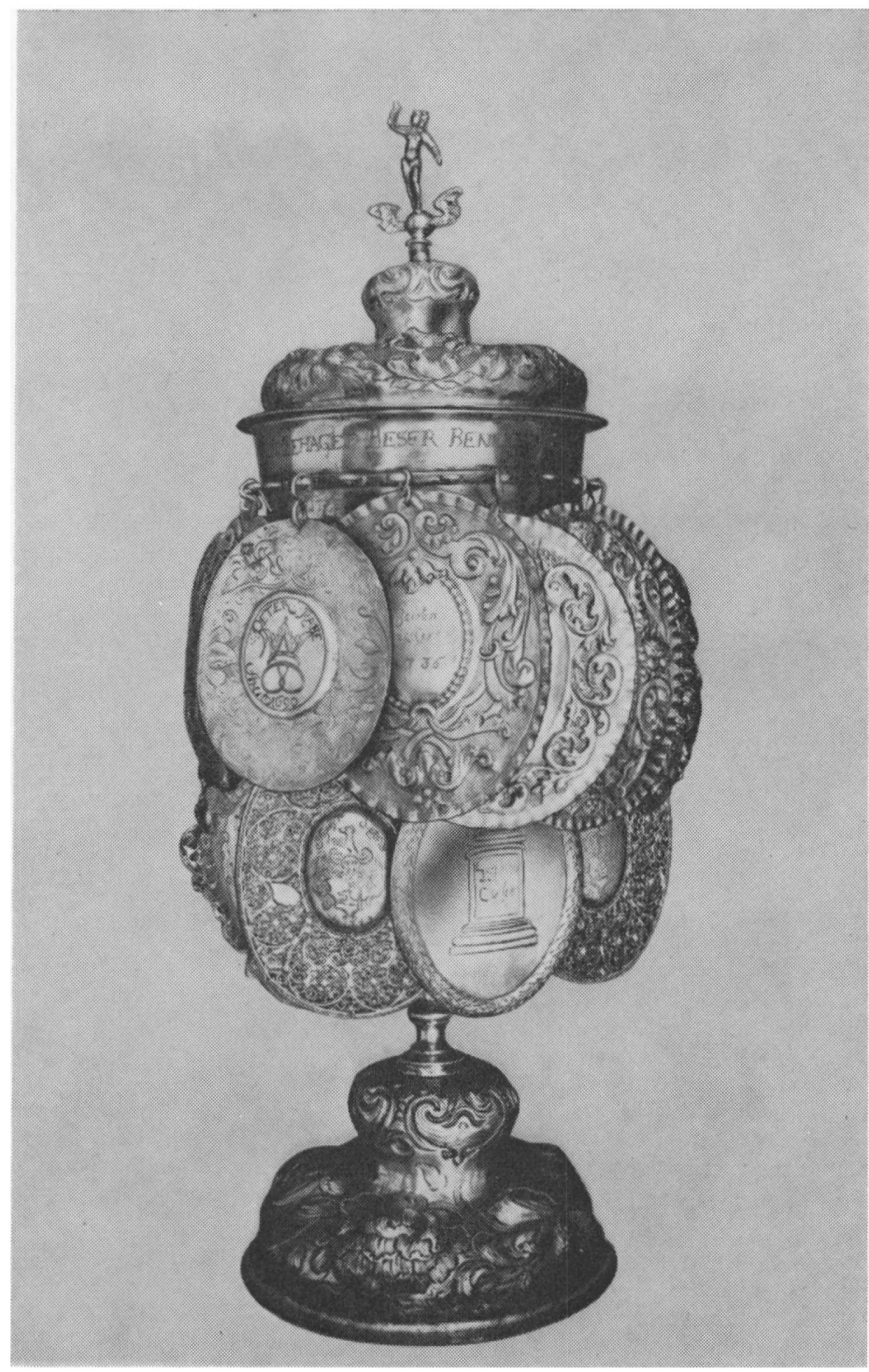

Fig. 12. Bager-velkomst. 1673. (FM 6512). Udfort af Evert Buros (nr. 67). $48 \mathrm{~cm} \mathrm{~h}$. Diam. $14.5 \mathrm{~cm}$. Lågpokal i akantusbarok. 43 skjolde, hvoraf de 8 er ældre end pokalen, resten fra tiden mellem $1675 \mathrm{og} 1824$. Fot. Flensborg Museum. 


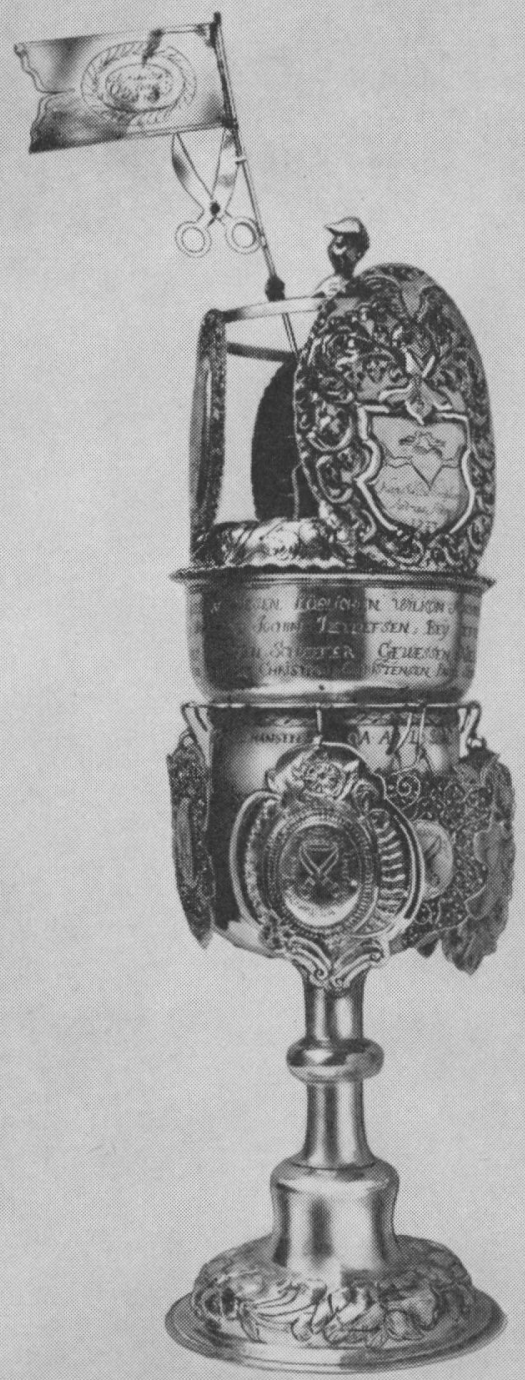

Fig. 13. Skrædder-velkomst. 1699. (LM 1929/42). Udført af Johan Jessen (nr. 75). $49.7 \mathrm{~cm}$ h. Diam. $14.6 \mathrm{~cm}$. Lågpokal i akantusbarok. 10 påhængte skjolde fra tiden mellem 1754 og 1794.

Fot. Schleswig-Holsteinisches Landesmuseum. 


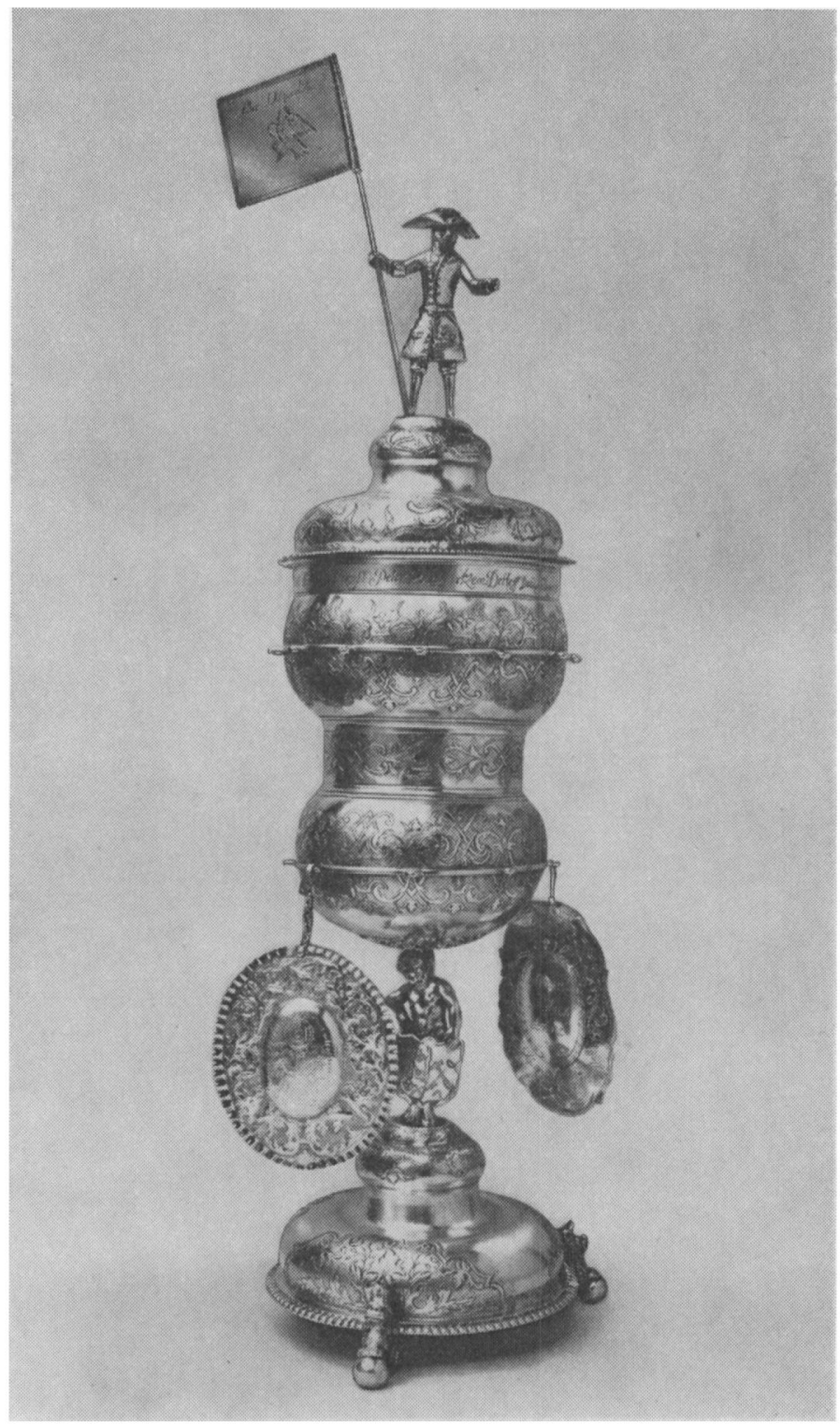

Fig. 14. Smede-velkomst. 1726. (LM 1929/41). Udfort af Severin Lorenzen I $(\mathrm{nr} .791 .54 .5 \mathrm{~cm}$ h. Diam. i foden $15 \mathrm{~cm}$. Lågpokal i akan. tusbarok. Kun to skjolde bevaret, fra 1731 og 1783.

Fot. Schleswig-Holsteinisches Landesmuseum. 


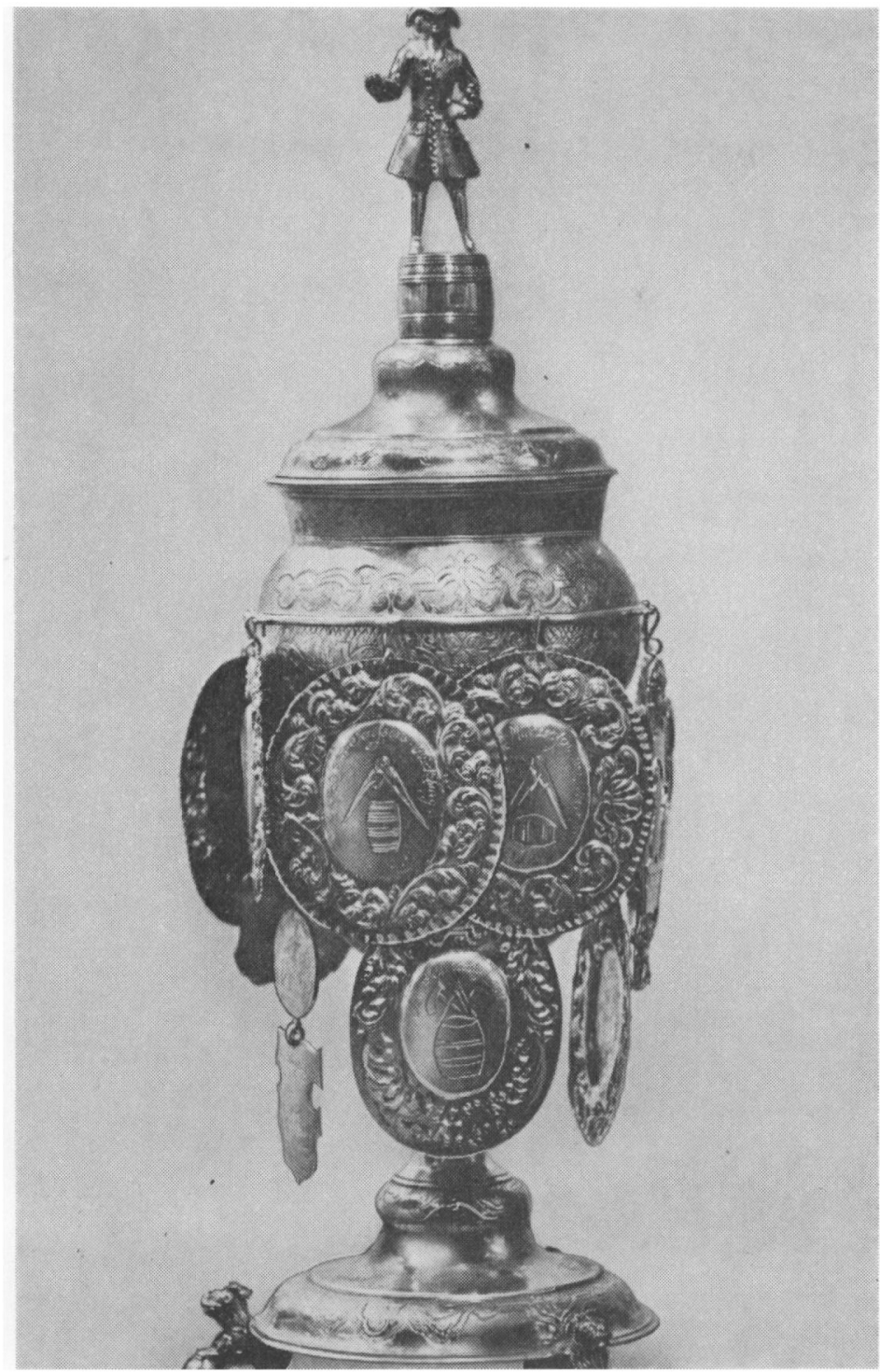

Fig. 15. Bødker-velkomst. 1742. (FM 20436). Udført af Paul Buchholtz (nr. 94). $52 \mathrm{~cm} \mathrm{~h}$. Fot. Flensborg Museum. 


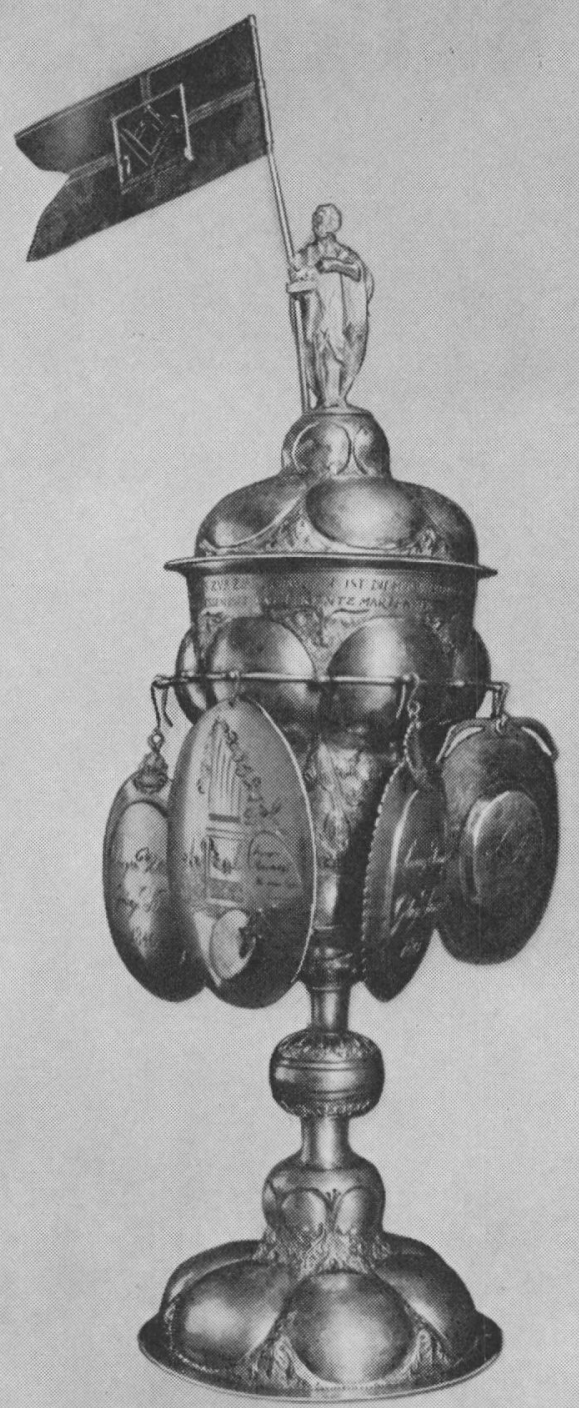

Fig. 16. Velkomst i S. Johannes (S. Hans) skyttegilde. 1721. (FM). Udført af Jürgen Matzen (nr. 81), 54 cm h. Lảgpokal med glatte bukler og akantusornamentering. I toppen er støbt S. Johs.-figur med fane fra 1805. 17 sølvskjolde fra tiden mellem 1735 og 1857. 7 senere.

Fot. Flensborg Museum. 


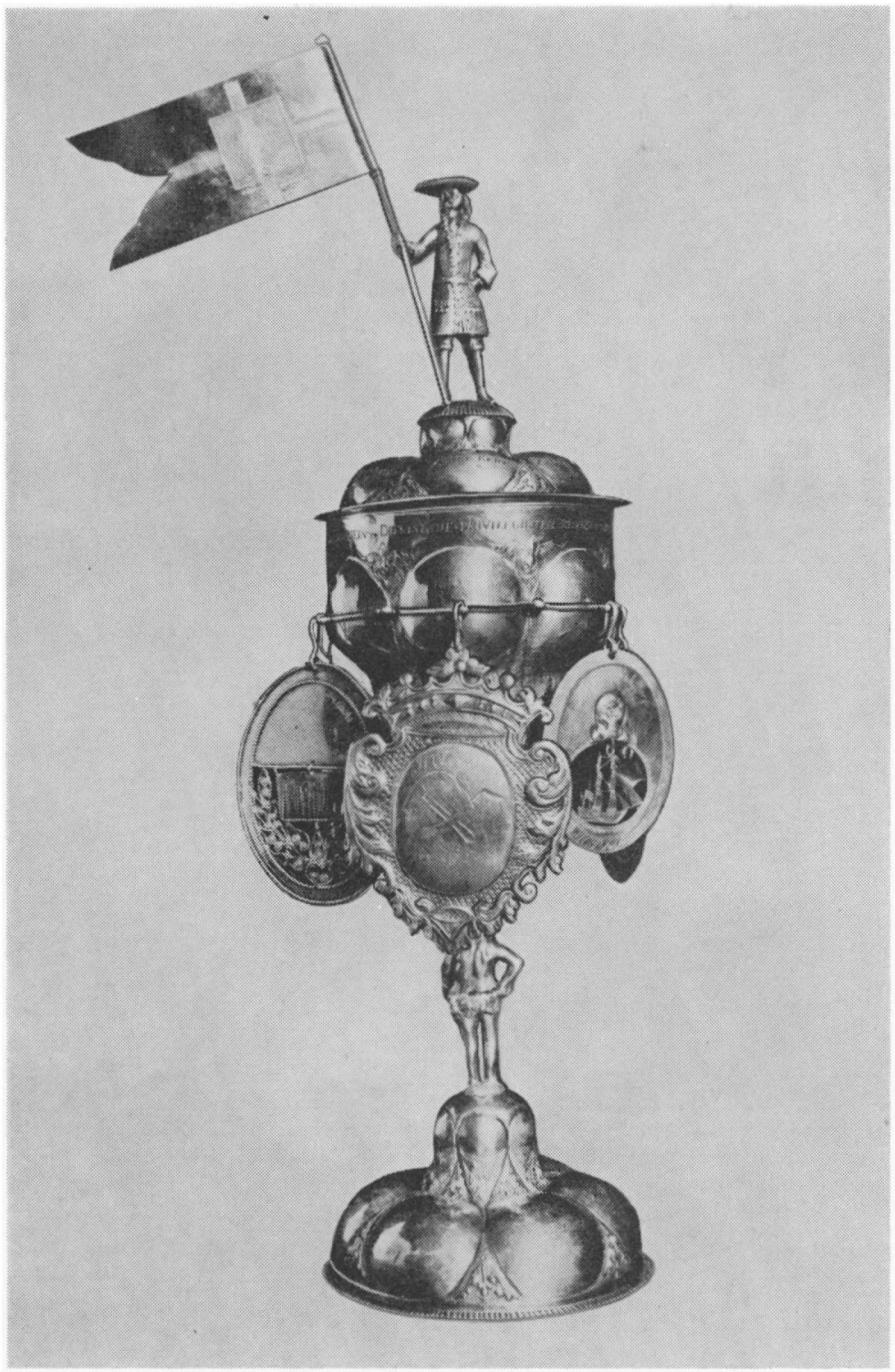

Fig. 17. Velkomst i S. Nicolai skyttegilde. 1721. (FM). Udført af Jürgen Matzen (nr. 81). $54.5 \mathrm{~cm}$ høj. Lågpokal som fig. 16. Det må antages, at også S. Johannes-pokalen har haft en Bacchus-figur som bærer af bægeret, så de to pokaler har været ens på nær topfigurerne, her en kavaler. 16 ældre skjolde fra tiden mellem 1785 og 1840.

Fot. Flensborg Museum. 


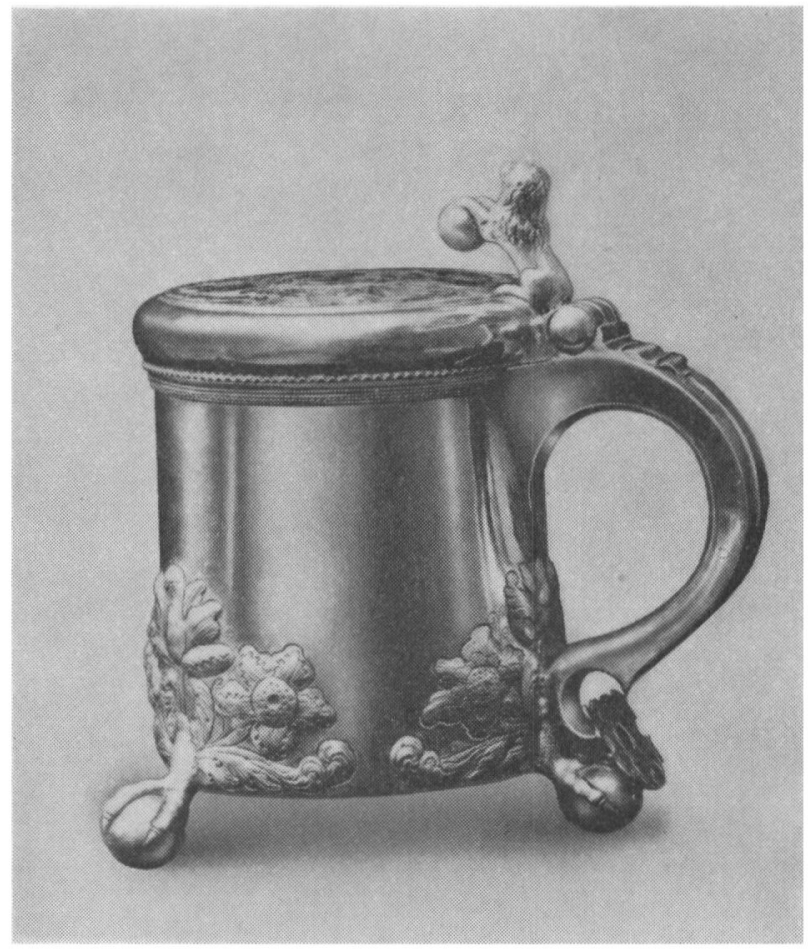

Fig. 18. Lågkrus i skipperlavet. O. 1700. Af ukendt mester LB. (FM 1889). $22 \mathrm{~cm} \mathrm{h.} \mathrm{Diam.} 13.6 \mathrm{~cm}$. Gedigent barokarbejde. Kugler med kløer og dreven akantusornamentering. På siden indgraveret over to krydsede ankre: Priviligirte SchifferGesellschaft, 1752. Som gæk en love med kugle. På låget et dobbeltvåben omgivet af en akantusranke.

Fot. Flensborg Museum. 


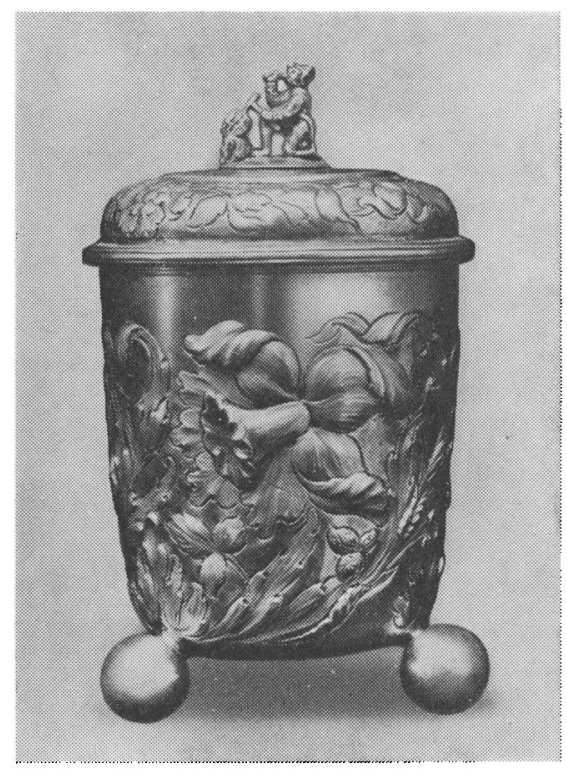

Fig. 19. Lågkrus uden hank. 0. 1700 . Antagelig udf. af Christopher v. Barm, der en kort tid var borger i Flensborg (nr. 73). Akantusbarok.

Fot. Flensborg Museum.

Fig. 20. Bæger i bagerlavet. 1760. Udført af Peter Steen I (nr. 97). (FM $6614) .8 .8 \mathrm{~cm} \mathrm{~h}$. Inscr.: Was Mier Gott Beschert Bleibt von Neidt Wohll Unverzehrt. Dethleff Sommer Altermann 1760.

Fot. Flensborg Museum.

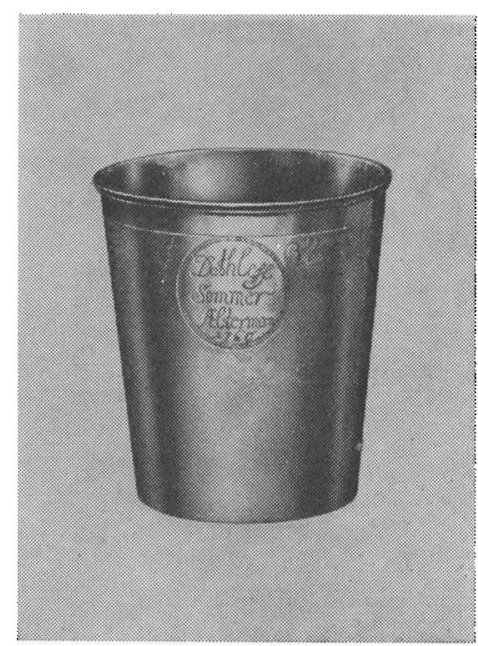




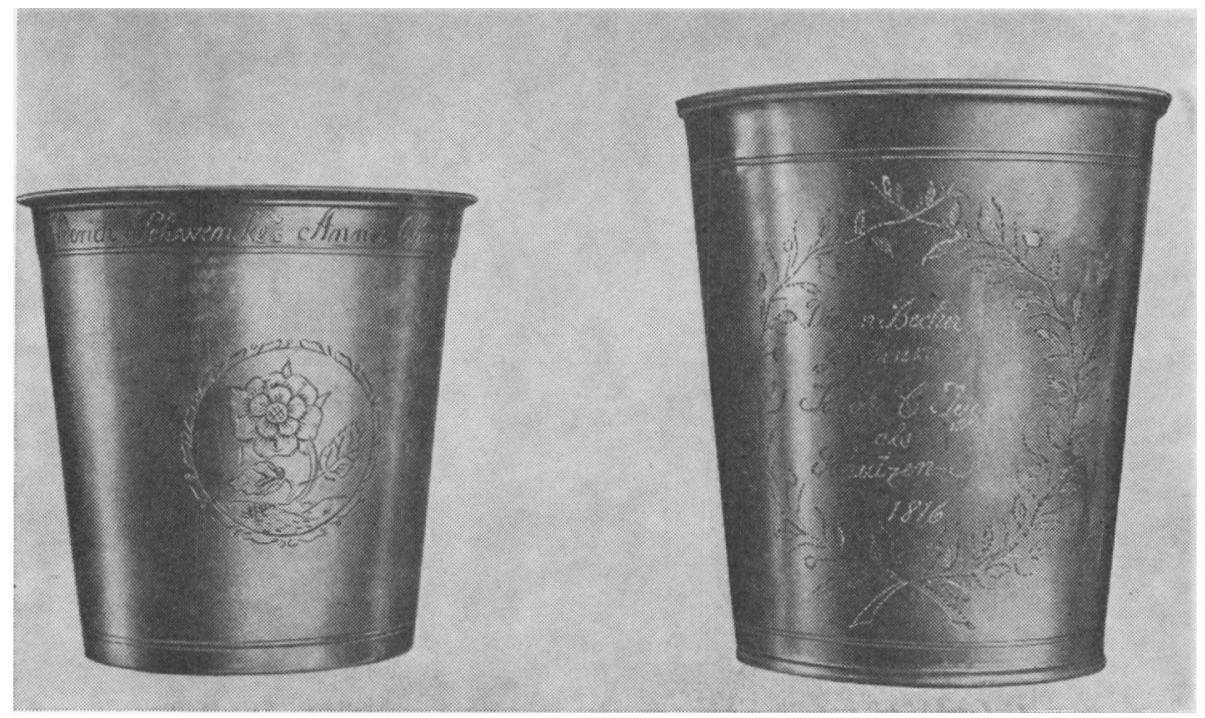

Fig. 21. 2 bægre i S. Nicolai skyttegilde. 1. 1769, udfort af Severin Lorentzen II (nr. 96). $8.6 \mathrm{~cm} \mathrm{h.} \mathrm{(FM} \mathrm{3914),} \mathrm{2.} \mathrm{1816,} \mathrm{udført} \mathrm{af} \mathrm{Hans} \mathrm{Balzer} \mathrm{(nr.} \mathrm{112).} 10.3 \mathrm{~cm} \mathrm{~h}$. (FM 3894). - Det forste indgraveret: Johann Friderich Schwenke Anna Christina Schwenkin von Drammen, det andet: Jacob C. Jäger. Fot. Flensborg Museum.

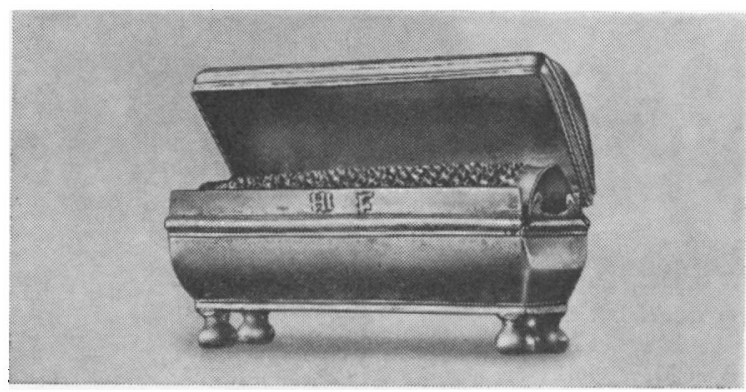

Fig. 22. Muskatrivejern i snedkerlavet. 1745. Udfort af Hinrich Jacobsen I (nr. 80). $3.5 \times 7 \mathrm{~cm}$. (FM 6160). Kisteformct med buet låg. Indgraveret cirkel, vinkelmål og lade i laurbærblade. Inscr.: der gesellen Reiff 1745. - Et af Flensborg Museums sjældneste guldsmedearbejder.

Fot. Flensborg Museum. 


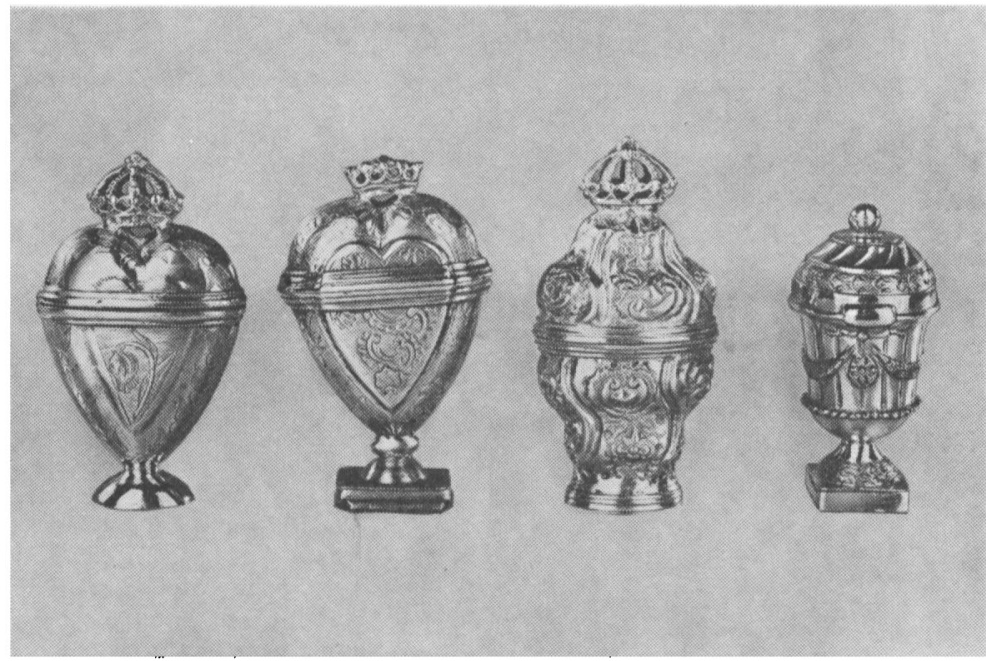

Fig. 23. 4 hovedvandsæg:

Nr. 1. W. C. Hansen (nr. 116). (LM 1930/249).

Nr. 2. Andr. Iversen (nr. 101). (LM 1935/927).

Nr. 3. A. F. Lehne (nr. 125). (LM 1924/94).

Nr. 4. Carl Wohlberg (nr. 113). (LM 1930/164).

Fot. Schleswig-Holsteinisches Landesmuseum.

Fig. 24. Sukker-strøske. 1833. Udført af Chr. Heinrich Hansen (nr. 134). (LM 1933/96).

Fot. Schl.-Holst. Landesmuseum.

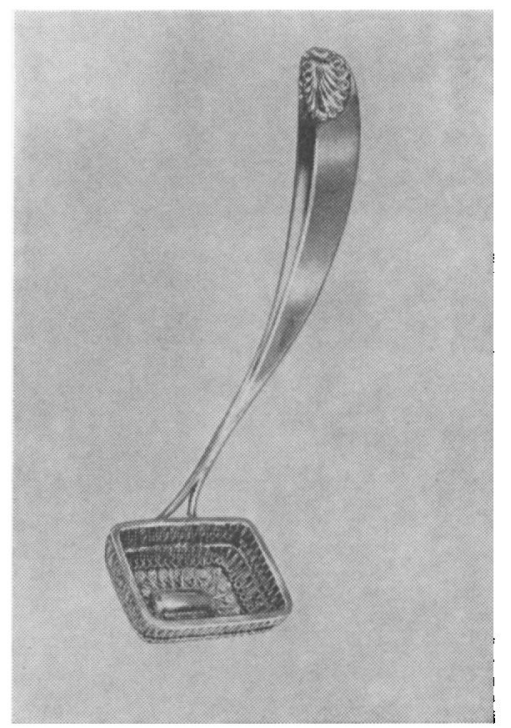


BYMARKERNE:

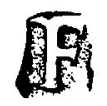

A.

(o. 1670)

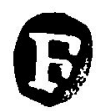

G.

(1707)

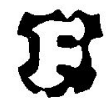

B.

(1672)

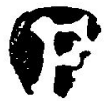

H.

(1711)

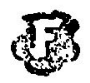

C.

(o. 1691)

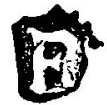

1.

(1714)

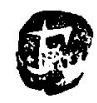

D.

(1699)

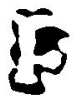

J.

(1725)

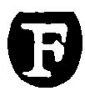

E.

(1700)

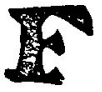

K.

(1726)

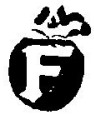

F.

(1707)

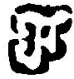

L. (1733)

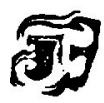

M.

(1758)

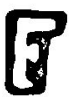

N. (1792)

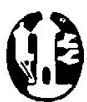

0 (1800-tallet)

(De gengivne by- og mestermærker er venligst stillet til rådighed af Landesamt für Denkmalpflege, Kiel.)

\section{UI DENTIFICEREDE MESTERMARKER:}

בG25 Skafferhammer i skipperlavet 1792. (KSF 348).

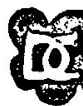

Lågkrus i skipperlavet 1612. (KSF 346).

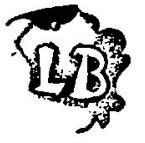

Lågkrus i skipperlavet. Ca. 1700. (KSF 348). Fig. 18.

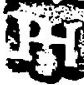

Oblatæske, Grundhof/Fl. (LKF 184).

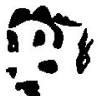

Skjold på bagervelkomst 1680. (KSF 331 f.). 


\section{MESTRENE:}

\section{HENRIK GULSMITH}

Giver o. 1400 gaver til S. Knuds Gilde. (S. I. 7).

2. MARTEN AURIFABER

Medl. af S. Laurentius Gilde o. 1400. (S. I. 84).

3. STRANGY AURIFABER

Medl. af S. Gertrudsgildet o. 1400. (S. I. 102).

4. LUDEKE GOLTSMYT

Medl. af Vor Frues Købmandsgilde o. 1420. (S. I. 237).

5. HEYSZE GOLTSMYT

Medl. af Vor Frues Købmandsgilde 1420, af Hellig Legemsgilde 1432-45, af Trefoldighedsgildet og husejer i Flensborg 1436. (S. I. 236, 391, 401, 420 og 81).

6. ANDERS GOLTSCMYT

Medl. af S. Gertrudsgildet o. 1430. (S. I. 117).

7. ENGHEILE GOLTSMYD

Medl. af S. Gertrudsgildet o. $1428 \mathrm{og}$ af Vor Frues Kobmandsgilde o. 1430. (S. I. 110 og 238).

8. NAMEN GHOLTSMYT

Medl. af Vor Frues Købmandsgilde o. $1430 \mathrm{og}$ af Hellig Legemsgilde 1432. (S. I. 238 og 391).

9. ALBERD GOLTSMEDE

Anklaget for suredelig behandling af udført guldsmedearbejde. (S. II. 892 ff.).

10. HANS BOSE GOLTSMIT

Medl. af S. Gertrudsgildet 1444, af Hellig Legemsgilde 1477 (S. I. 120 og 393).

11. KERSTEN GOLTSMIT

Medl. af Vor Frues Kobmandsgilde o. 1445. (S. I. 242).

12. THOMYS GOLTSMYT

Medl. af Vor Frues Købmandsgilde o. 1445. (S. II. 318).

13. KÖPIKE GOLTSMYD

Medl. af S. Gertrudsgildet o. 1450 (S. I. 111) og af Vor Frues Købmandsgilde u. å. (S. I. 256).

14. TYCKE GOLSSMYT

Medl. af Dragernes Gilde 1450. (S. I. 152). 
15. PETER GOLDSMID

Medl. af Vor Frues Købmandsgilde o. 1458 og 1466. (S. I. 245 f.).

16. HERMAN GOLTSMID

Medl. af Vor Frues Købmandsgilde. (S. I. 245).

17. HANS GOLTSMYT

Medl. af Vor Frues Købmandsgilde 1472 f. (S. I. 247).

18. BERTEL GHOLTSMYT

Medl. af Hellig Legemsgilde 1475. (S. I. 389).

19. HANS MOREKEN GHOLTSMYT

Medl. af Hellig Legemsgilde 1475. (S. I. 392).

20. HANS MARKE GOLTSMYT

Medl. af Hellig Legemsgilde 1478.

21. GODEKE GOLTSMYT

Medl. af S. Gertrudsgildet u. å. og af Hellig Legemsgilde 1481 (S. I. 104 og 394). Omt. 1496. (S. I. 649 og 651). Hans hus solgt 1518. (Sch.).

22. TONNYES GOLTSMYDT

Medl. af Hellig Legemsgilde 1494. (S. I. 396).

23. CLAWES GOLTSMYTH ECKLEFF

Medl. af Vor Frues Købmandsgilde 1486, af Hellig Legemsgilde $1488 \mathrm{og}$ af Den hellige Trefoldigheds Gilde 1495. (S. I. 250, 395, 70 og 73). 1498 er han oldermand. (S. I. 720). 1517 får sønnen Hans Eckleff skøde på hans hus af enken.

24. KASTEN GOLTSMYT

Medl. af Vor Frues Købmandsgilde 1504. (S. I. 252).

25. CORTH GOLTSMITH

1514 ejer han hus nr. 418 i S. Marie sogn (Sch.) og er kirkeværge. (S. II. 97). Medl. af Hellig Legemsgilde 1521. (S. I. 401). Endnu nævnt 1562. (Sch.).

26. JACOB GOLSMITH

Medl. af Hellig Legemsgilde 1514. (S. I. 400), anført som husejer 1518-33. (Sch.). Endnu omt. 1550. (S. II. 319).

27. HANS GOLTSMIT ECKLEFF

1517 husejer. Medl. af Vor Frues Købmandsgilde 1519, af Den hellige Trefoldigheds Gilde 1537, sælger hus 1553. (Sch.). 1556 anbefaler Chr. III at man overlader ham hus på Vor Frue Kirkeplads. (S. II. 655), og 1558 befaler Chr. III Korsør at modtage Hans G. (S. II. 828). 
28. LAUERENS GOLTSMYDT

1519 kober han hus og igen 1547 hus nr. 271 i S. Marie sogn. (Sch.). Medl. af Vor Frues Købmandsgilde 1521. (S. I. 255). Omt. som giver til Vor Frue kirke o. 1550. (S. II. 320 f.). Formentlig identisk med den Lauerens Boisen de olde, som dør 1573. (R. 225). Datteren g. m. Baltzer Wegener 1561. (R. 63).

29. THOMAS GOLTSMITH

Ejendomme nævnt 1520, 1530 og 1537 hus nr. 473 i Angelbogade. Han sælger det 1550. (Sch.).

30. ASMES MALER GOLDSCHMIDT

Død 1564. (R. 110).

31. ASMUS PETERSSON GOLTSZMIT

1548 omtalt i skøderne, og 1549 i Stadbok. (S. I. 441), men her som Rasmus P., ligeledes i borgerbogen 1560, if. den fra Vilsbæk. Medl. af Hellig Legemsgilde 1556 f. (S. I. 412). Gift 1564. (R. 105). Huset solgt 1566. (Sch.).

32. BERNT GOLTSMYT

1551 modtager han af Vor Frue Gilde 2 pund, 2 lod og 1 kvint sølv til at fremstille kroner af. (S. I. 699), og 1553 bortskøder han sit hus nr. 447 i $\mathrm{S}$. Nicolai sogn.

33. LAUERENS BOISEN

Formentlig søn af Lauerens Goltsmydt. Mulig identisk med den Laurids Boessan, der er omtalt i Kobenhavn 1564-66 og 1570. (Boje 2. 35). I en fodselsattest for sønnen 2. juni 1585 hedder det nemlig: Ist als Goldschmied in kgl. Dienst in Kopenhagen (retsprot. II. 188). Hus solgt 1584. Død s. å. (KR.).

34. HANS HACKE

Omt. 1598. (RP. III. 347 f.). Konen d. 1563. (R. 96). Sælger hus 1565. (Sch.).

35. HINRICK KOCK

Omt. som guldsmed 1597. (RP. III. 286 f.). Hus i S. Johs. sogn 1575. (Sch.). D.: 1583. (R. 457).

36. BALTZER WEGENER

B.: 1561. (BB, nr. 13). G.: 1561 med en datter af nr. 28. 1584 af Peter Rantzau udnæunt til byfoged. (R. 486). 1574 erhverver han hus i Ramsherred (S. Marie sogn). D.: 1602. (R. 1524). Døtre g. m. nr. 38 (R. 356) og nr. 39 (R. 417).

Arbejder:

Kalk og disk 1569. Steinberg/Fl. (KLF 344). Fig. 2.

M.:

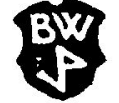


37. DIRICK HARMENS

1566 g. m. enken til nr. 30. 1581 med enken til nr. 28. (R. 142 og 391). D.: 1592. (R. 888).

38. HANS PETERSEN

1580 g. m. datteren af nr. 36. (R. 356). Fra Ditmarsken. D.: 1598. (R. 1247).

39. PAWEL REKERT

1582 g. $m$. datteren af nr. 36. (R. 417). D.: 1602. (R. 1509).

40. NIS KEIRSTENS

B.: 1585. (BB nr. 6). D.: 1603. (R. 1607). Hus solgt 1605. (Sch.).

41. PETER SPEGEL

B.: 1586. (BB nr. 17). G.: 1586. (R. 598). 1589 får han skøde på Asmus Petersens hus i S. Marie sogn, hus nr. 11. D.: 1590. (R. 789). Enken g. m. nr. 44.

42. PETER TUXEN

B.: 1588. (BB). D.: 1604. (R. 1623, KR). Fra Hacksted. (RP. III, 13).

43. I,UTKE KLOEN

1589 skænker han et vindue til Maric kirke. (R. 1589). 1596 leverer han beslag til heste og bosser for 590 rdl. til hertugen af Gottorp. (Regnsk.). 1617 klage over sølv til et balte han har leveret. (St. Fl. 971. 1).

44. JOHAN HARDER

B.: 1590. (BB nr. 2). 1591 g. m. enken til nr. 41. Arbejde for Christian IV 1594. (Bering Liisberg 144). Kirkeværge 1603. (R. 845 og 1615). Dod for 1614. (Sch.).

45. TONIES GOLTSMIDT

1596 gifter en stifdatter sig. (R. 1054).

46. NIS JUVELER

1595 s wart Nis Jweler upgehenget und 10 Dage darna syne Frowe by ehm «. (R. 1122).

47. JU'RGEN DUGGE

G.: 1596. (R. 1170).

48. LAUERENS CHRISTENSEN

Omt. 1597. (RP. III. 286 f.). D.: 1601. (R. 1435).

49. PETER KOCK

Son af nr. 35. Lærling hos nr. 48 i 4 år. (RP. III. 286 f.). 
50. MICHEL ANDERSEN GOLTSMIT

1598 dør hans kone og to børn. (R. 1283). 1599 nyt ægteskab. (R. 1349). D.: 1611. (KR).

51. ANDREAS KOCK

Søn af nr. 35 . Omt. 1603 i anledning af at han vil rejse til Aurich. (RP. IV. 159 f.).

52. CARSTEN GOLTSMIT

G.: 1603. (R. 1612).

53. MICHELL GROTT

Omt. 1604. (Kr). D.: 1608. (KR). S. Nicolai s.

54. CLAUS PETERSEN

Son af nr. 38. Omt. som guldsmedesvend 1608. (RP. IV. 351).

55. HEINRICH HARDER

Omt. som guldsmed 1608/09. (KR), men Reinhusen betegner ham 1594 som sværdfeger. (R. 1034).

56. HANS KLOEN

Søn af nr. 43. Omt. 1609, da han som guldsmedelærling vil rejse til Danzig. (RP. IV. 388 f.).

57. DIDERICH KAPMAN

Omt. 1609 som guldsmedesvend fra Bielefeld. (Kr) og 1633 (KR).

58. PETER DOER

Omt. 1610. $(\mathrm{Kr})$.

59. CONSTANTIUS HACKE

Omt. 1610 som guldsmedesvend fra Danzig (Kr) og 1611 fra Kobenhavn (BB).

60. NICOLAUS HACKEMAN

Omt. 1611. (Kr, nr. 22).

61. PETER BUROS

1615 erhverver han hus nr. 44 i S. Marie s. (Sch) og er omt. i samme kilde 1633 og 35 . Formentlig far til nr. 66.

Arbejder:

Kalk 1618. Ullerup/Sø. (Arkivalsk dokumenteret). DK 2254. Fig. 3.

62. ANDREAS PETERSEN

1622 husejer i S. Nicolai s. (Sch). 1624 sælger han to diamantringe på Glücksborg til hertugen for 110 rdl. (Regnsk. 76. 423). 1625 proces mod perlestikkeren Heinrich Wesselink. Omt. 1633 og 1638 (Sch). Hans hus nævnt i skatteregnsk. endnu 1650. 
63. JÜRGEN LEMBECK

Omt. 1624'25. (Kr, nr. 1). 1633 skode på hus nr. 419 i S. Marie s. (Sch). Konen dør 1659. Omt. i Kbh. 1655. (Bøje 2. 44). Død før 1672. (Sch).

Arbejder:

Kalk 1648. Jörl/Fl. KLF 222.

M.: L (i oval)

64. REIMER PHIIIP

B.: 30. 1. 1626. Omt. 1624/25. (Kr. nr. 2).

65. PAUL KUI.L

Omt. 1636/37. Fra Rendsborg. (Kr.).

66. HANS BUROS

Son af nr. 61 ? Omt. i skatteregnsk. 1650 ff. (St. Fl. 210). Indehaver af hus nr. 44 i $S$. Marie s., men ojensynlig boende i S. Nicolai s. Far til Jorgen B., der får borgerskab i Kobenhavn 11. 6. 1675 og bliver dronningens guldsmed (Boje 2. 47), til Hans II, der 1669 soger til Danzig (Geburtsbrief 23. marts 1669) og til Evert, der 1671 omt. som Goldarbeiter i Kobenhavn (St. Fl., C. XIX 1. 18). Formentlig dod 1661.

Arbejder:

Låg til snedkerlavets drikkehorn 1656. Museum für Kunst und Gewerbe, Hamburg, 1898/104. (KSF 340).

67. EVERT BUROS

Son af nr. 66. 1647 overtager han hus nr. 44 i S. Marie. Omt. i skatteregnskaherne 1650 f. (In der Heiligen Geist Gange). D.: 1690 (KR).

Arbejder:

Alterkande 1646. Tonder k. (DK 957). Fig. 4.

Alterkande 1649. Klostret Fl. FM 1923/2. (KSF 267).

Bager-velkomst 1673. FM 6512. (KSF 330). Fig. 12.

M.:

68. HEINRICH MATTHIESSEN

B.: 31. 1642. (o. 1620-1713). Fra Als. 1664 indehaver af hus $n r$. 409 i S. Nicolai s. (Holm 68). 1707 købes det af svigersønnen Hinrich Block.

Arbejder:

Kalk + disk 1665. Sottrup/Sø. (DK 2236). Fig. 5.

Sygekalk 1669. Ockholm/Hus. (KKH 186.

Sygekalk + disk 1672. Hürup/Fl. (KLF 201).

Kalk + disk 1674. (Ibid).

Disk 1675. Wallsbüll/Fl. (KLF 363).

Kalk + disk 1682. Nordhackstedt/Fl. (KLF 258).

Kalk + disk 1686. Bjolderup/ $/$. (DK 1837). 
Kalk + disk 1693. Sörup/Fl. (KLF 320).

Kalk + disk 1695. Holbsl/So. (DK 2018).

Kalkfod. u. ‥ S. Johs./Fl. (KSF 226).

8 skjolde på Fl. bagervelkomst 1661-91. FM 6512. (KSF 330).

Bæger i rebslagerlavet $u$. å. FM 8533. (KSF 335).

M.:
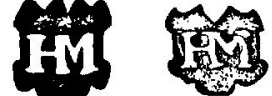

69. HANS MELCHERTSEN

B.: 21. 1. 1661. Fra Rendsborg. 1675 erhverver han hus $\mathrm{nr} 116 \mathrm{i}$

S. Johs. s. (Sch). Omt. 1677/78. (BB, Kr).

70. CONRAD PULLTZER

B.: 13. 2. 1671. Ansøgning 1670 , hvoraf fremgår at han er guldsmedesøn. (St. Fl. 971. 1).

71. MELCHIOR SCHWEDER

B.: 1677. (KGP 8. 103). Henstand med gebyret, da seine Mittel gering und die Zeiten beschwerlich sind .

Arbejder:

Kongeskjold for S. Nicolai skyttegilde. u. A. (KSF 342).

M.: $\quad M S(+22)$

72. DETLEF BUROS

1681 erhverver han hus nr. 403/04 i S. Marie s. (Sch). $1692-$ omtalt som Goldarbeiter - sæIger han samme hus.

Arbejder:

Alterkande 1655. Gelting/Fl. (KLF 132 f.).

M.: 10

73. CHRISTOPH von BAHIREN

B.: 14. 2. 1687. Antagelig identisk med Christopher v. Barm, Sdb. Arbejder:

Lågkrus. Fig. 19.

M.: CB (i ring)

74. HINRICH BLOCK

B.: 14. 2. 1687. (o. 1654-1733). Fra Frederiksstad. (KGP 25). Svigerson til nr. 68. Fra 1688 boende Holm 68 (H. Matthiessens ejendom). 1714 sælger han huset til svigersønnen, nr. 80.

Arbejder:

Oblataske 1700. Asbøl/A. (DK 1912). Fig. 6.

Oblatæeske 1700. Gråsten/ $\bar{A}$. (DK 1926).

Oblataeske 1704. Munkbrarup/Fl. (KLF 242).

Kalk + disk 1704. Nybøl/Sø. (DK 2274). 
Kalk + oblatæske + alterkande 1708. Nordborg/Sø. (DK 2184). Fig. 7-8.

Kalk 1709. S. Marie/Fl. (KSF 124).

Oblatæske. Klostret/Fl. 1716. (KSF 267).

Oblatæske. u. ̊. S. Johs./Fl. (KSF 226).

Oblatæske. u. å. Boren/Sl. (KLS 162).

3 skjolde på bager-velkomst 1691 f. FM 6512. (KSF 332).

Bæger i S. Nicolai skyttegilde 1723. (KSF 343).

Ialgkrus i skipperlavet. o. 1700. FM 6386. (KSF 348).

\section{м.: $\quad 838$}

75. JOHAN JESSEN

B.: 10. 2. 1696. (-1717). Fra Siverstedt. Omt. 1695/96. (BB, Kr).

G.: 1696. 1704 erhverver han hus i Holm. Yderligere nævnt 1711 og 1714.

Arbejder:

Kalk $1700+$ oblatæske 1707. Steinberg/Fl. (KLF 344).

Sygekalk + disk 1711. Adelby/Fl. (KLF 94).

Kalk + disk 1711. S. Nicolai/Fl. (KSF 186).

Kalkfod u. å. S. Johs./Fl. (KSF 226).

Skræddersvendenes velkomst 1699. LM 1929/42. (KSF 337).

Fig. 13.

Skjold på bagervelkomst 1702. FM 6512. (KSF 332).

M.:
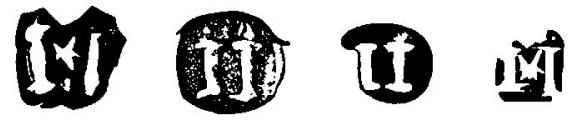

76. JOHANN STEEN

D.: 1723. S. Marie. (KR).

77. CHRISTIAN LÜBECKER

B.: 20. 2. 1702. (1661-1739). S. Nicolai. (Skatteregnsk.). Borger $i$ Kbh. 23. 11. 1712. (Bøje 2. 62).

Arbejder:

Oblataske 1707. Wanderup/Fl. (KLF 368).

M.:

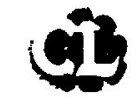

78. DAVID STEEN

B.: 5. 3. 1703. (o. 1680-1726). Erhverver ejendommen nr. 11 i S. Marie sogn 1712. Muligvis søn af nr. 76.

Arbejder:

4 skjolde på bagervelkomst 1707/15. FM 6512. (KSF 332).

M.:

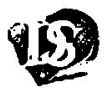


79. SEVERIN LORENZEN (I)

B.: 6. 2. 1708. (o. 1680-1740). Fra Haderslev-egnen. (KGP 11. 142). Erhverver 1708 hus nr. 114 i Ramsherred i S. Marie s. (Sch). Enken fortsætter virksomheden.

Arbejder:

Smedesvendenes velkomst 1726. LM 1929/41. (KSF 337). Fig. 14. Skjold på samme. Ibid. 1731.

Oblatæske 1733. Gross Solt/Fl. (KLF 327).

Skipperselskabets olkande 1709. FM. (KFS 346 f.).

M.:

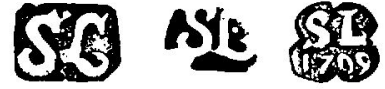

80. HINRICH JACOBSEN (I)

B.: 11. 2. 1715. (1691-1769). S. Nicolai. Fra Angel. (KGP 16. 678). Erhverver 1714 svigerfaderen, Hinrich Blocks ejendom, hus nr. 409 i S. Marie. (Sch).

Arbejder:

Sygekalk 1735. Sottrup/Sø. (DK 2237).

Sygesæt $1735(+)$. Ullerup/Sø. (DK 2254).

Sygesæt $1739(+)$. Broager/Sø. (DK 2314).

Sygesæt $1743(+)$. Nybøl/Sø. (DK 2275).

Oblatæske. u. å. Adelby/Fl. (KLF 94).

Skjold på bagervelkomst 1737. FM 6512. (KSF 333).

Snedkersvendenes muskat-rivejern. 1745. FM 6160. (KSF 341). Fig. 22.

Bager. 1740. FM 15482.

Spiseske ti rottehale. 1728. FM (OB 228).

M.:

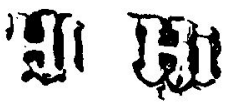

81. JURGEN MATZEN

B.: 13. 2. 1719. (o. 1695-o. 1753). S. Nicolai. G. m. enken til nr. 75. Sælger sin ejendom 1753. (Sch).

Arbejder:

2 kalke +1 disk 1747. Broager/Sø. (DK 2312).

2 alterbordsskjolde 1752 (+) Ibid. (I)K 2308).

Sygesæet u. ả. Deezbüll/ST. (KKS 78).

Velkomst i S. Nicolai skyttegilde 1721. FM. (KSF 343). Fig. 17.

Velkomst i S. Johs. skyttegilde 1721. FM. (KSF 341 f.). Fig. 16.

Skjold på bagernes velkomst 1714. FM 6512. (KSF 332).

Rebslagernes drikkebæger 1725. FM 6512. (KSF 335).

Skjold på hattemager-velkomst $\mathrm{i}$ Kbh. 1752. NM 3.

M.:

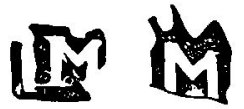

82. PETER FRANTZEN

B.: 5. 2. 1725. (Sch og Kr). S. Nicolai. Omt. 1740. (Sch). 
83. JOHANN NICOLAI STEEN

B.: o. 1725. (1704-68). Son af nr. 78. Køber faderens hus 1745 .

Enken omtalt i Fo. 1769. Hun sælger huset 1768. (Sch).

Arbejder:

Oblataske 1760. Westerland/ST. (KKS 390).

Sukkerbøsse. FM 6403.

2 bægre 1757. S. Johs. skyttegilde. FM 3897. (KSF 344).

M.:

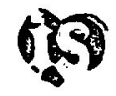

84. MARCUS von BARM

B.: 12. 2. 1731. Son af guldsmed Jacob v. Barm i Tarup. (170684). (KGP 12. 216).

85. HANS CHRISTIAN BILLHARI)

B.: 6. 2. 1736. (-1739). Fra Ábenrå. (KGP 14. 148). S. Nicolai s. Arbejder:

Skjold på slagternes velkomst 1723. FM 5591. (KSF 335).

\section{M.: FirB}

86. CHRISTIAN PETERSEN

B.: 6. 2. 1736. Fra Fredericia. (KGP 14. 2).

87. JOHANN CHRISTIAN ULICH

B.: 18. 2. 1737. (-1750). Kaldet Goldarbeiter.

Arbejder:

Kalk + disk. u. à. Sterup/Fl. (KLF 355).

M.: ICU (i rektangel)

88. IVER RUDOI.F von BARM

Omt. 1737/38. $(\mathrm{Kr})$. Identisk med Haderslev-guldsmeden. (Bøje 2. 183).

89. HINRICH WILHELMSEN

B.: 10. 2. 1739-1740. S. Marie.

90. LORENZ JACOBSEN

B.: 22. 2. 1740. (1710-93). S. Marie. Hans ejendom i Ramsherred overtages 1758 af nr. 100. (Sch). Siden mester i Gråsten.

91. PAUL BENDIXSEN

B.: 20. 2. 1741. G.: Bredsted 1739. Jvf. St. 94.

92. HANS HERMANSEN HOLM

B.: 22. 2. 1745. Fra Nakskov. (KGP 16. 678). Formentlig søn af Herman Corditzen Holm. (Bøje 2. 220). 
93. BEREND SCHULTZ

B.: 6. 2. 1747. Skatterestant 1750 .

94. PAUL BUCHHOLTZ

B.: o. 1740. (1711-67). Efter en gl. kunsthảndvarkerfamilie i Fl. Frhverver ejendom i S. Nicolai 1748. Sælger igen 1763 og dor som en fattig mand.

Arbejder:

Bødkersvendenes velkomst 1742. FM 20136. Fig. 15.

M.: PBH (i rektangel)

95. ANDREAS HINTZ

B.: 14. 2. 1752. Kaldet Goldjubilierer. Hus nr. 626. Fo. 1769.

Arbejder:

Svajknækket kaffekande 1769. FM 9833.

M.: AH (i kvadrat)

96. SEVERIN LORENTZEN (II)

13.: 22. 2. 1754. (1719-88). Son af guldsmed Jürgen Lorentzen, Tonder. G. m. datter af nr. 79. Fo. 1769. S. Marie. 2 svende. Salger sit hus 1782. (Sch).

Arbejder:

Bager i S. Nicolai skyttegilde 1769. FM 3894. (KSF 343). Fig. 21.

97. PETER STEEN (I)

13.: o. 1755. Søn af nr. 83 ? (d. 1759). Får 1755 skude på hus nr. 46 i S. Marie s. (Sch).

Arbejder:

Drikkebæger i bagerlavet 1760. FM 6614. (KSF 333). Fig. 20.

M.:

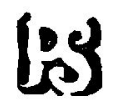

98. JACOB JACOBSEN

B.: o. 1755. (1721-96). Son af nr. 80. Erhverver ejendom i S. Johs.

1755, og han sælger den 1776. (Sch). Fo. 1769.

Arbejder:

Kalk 1773. Nordhackstedt/Fl. (KLF 259).

Kalk + disk 1775. Struxdorf/Schl. (KLS 479).

Bager i S. Johs. skyttegilde 1758. FM 3894. (KSF 344).

Skjold på bagervelkomst 1784. FM 6512. (KSF 333).

Skjold på $S$. Nicolai skyltegildes velkomst 1786. FM 3894. (KSF 342 ).

Skjold pai slagtervelkomst 1785. FM 5591. (KSF 336).

Spiseske, rokoko. FM 20662.

M.:

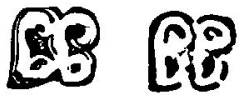


99. JOHAN RIEBER

B.: 28. 2. 1757. (1726-75). Fra Vordingborg. Husejer 1758 i S. Nicolai s.

Arbejder:

Bæger. Inscr.: Ellen Lorenzen Lauterup. FM 3392.

M.: JR (ligatur i ring)

100. BARTHOLD BARTHELSEN

B.: o. 1758. (1726-78). Fra Haderslev? Overtager 1758 Lorenz Jacobsens ejendom i Ramsherred, hus nr. 138. (Norregade 79). (Sch). Går fallit 1768. (Sch). Fo. 1769.

101. ANDREAS IVERSEN

B.: 16. 2. 1761. (1729-95). Hus nr. 46 i S. Marie s. (Storegade 77). Arbejder:

Kalk 1783. Esgrus/Fl. (KLF 121).

Hovedvandsæg. Vase. LM 1935/927. Fig. 23.

Hovedvandsæg. Vase. LM 1935/2015.

Spiseske med flusser. LM 1915/11.

Hovedvandsag. Fisk. LM 1934/25.

Hovedvandsæg. Fisk. 1793. FM 8446.

2 kaffeskeer. 1792. FM 11392.

6 rokoko teskeer. FM 14341.

Skjold på slagterlavets velkomst. 785. FM 5591.

M.:

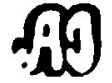

102. MARTIN KREBS

B.: o. 1761. (1737-75). Erhverver 1761 hus nr. 351 i Kompagnigade. Fo. 1769.

103. FRIEDRICH CHRISTIAN RICHTER

B.: 4. 3. 1765. (1730-1816). Fra Kolding. S. Marie s. Fo. 1769.

104. NICOLAI JACOBSEN

B.: o. 1769. (1733-99). Son af nr. 80. 1769 overtager han faderen, Hinrich Jacobsens hus, nr. 505, i Angelbogade. (Sch). Fo. 1769.

105. HANS THUN

B.: 18. 2. 1771. (1741-1823). G. m. datter af nr. 96. Hus nr. 70 i Mariegade. Fo. 1803.

Arbejder:

Kalk, disk og oblatæske 1796. Bov/A. (DK 2034). Fig. 9.

Hovedvandsæg. Fisk. FM 2217 og 19306.

M.: HT (i rektangel) 
106. HINRICH JACOBSEN (II)

B.: o. 1775. (1751-1811). Søn af nr. 98. Hus nr. 726 i Johannesg. Fo. 1803.

107. FRIEDRICH von BARM

B.: 16. 8. 1777. Son af Rudolph v. B., Haderslev. G. m. datter af nr. 88.

Arbejder:

Skafferhammer i S. Johs. skyttegilde 1796. FM 3894. (KSF 344). Kaffeske o. 1790. FM 113920.

M.:

\section{HANS CHRISTIAN BOYSEN}

B.: 14. 2. 1778. Fra Logumkloster. S. Marie s. Hus nr. 351.

Arbejder:

Kalk 1783. Helligåndskirken. (KSF 246).

Skjold på smedesvendenes velkomst 1783. LM 1929/41. (KSF 337)

Skjold på slagterlavets velkomst 1807. FM 5591. (KSF 336).

'Tabatiere. FM 9853.

Sukkerskål. 1790. Priv.eje Århus. Inscr.: H. C. Göttig.

\section{M.: ACB}

109. PETER STEEN (II)

B.: o. 1785. (1755-1835). Søn af nr. 97. Hus nr. 608 i Storegade. Fo. 1803.

Arbejder:

Oblatæske 1794. Treia/Schl. (KLS 540).

Skjold på bagervelkomst 1793. FM 6512. (KSF 333).

Skafferhammer i slagterlavet 1809. FM 5591. (KSF 336).

Skjolde på slagtervelkomst 1795 og 1800 . FM 5591.

1 par skospænder. FM 6434.

M.: SS

110. JENS JACOBSEN

B.: o. 1787. (1757-1844). Søn af nr. 98. Hus nr. 305 i Storegade. Fo. 1835 og 1803.

111. HANS THOMAS HAASE

13.: 14. 9. 1788. Son af Chr. Haase, Haderslev.

Arbejder:

Skipperlavets pokal 1796. Arnis/Schl. (KLS 118).

\section{м.: HJH}


112. HANS BALZER

B.: 3. 3. 1794. (1769-1841). Hus nr. 405 i Storegade. Fo. 1835.

Deputeret borger.

Arbejder:

2 kalke + oblatxeske 1795. Bramstedt/Seg.

Kalk u. i̊. sst.

Skjold på filtmagerlavets velkomst 1829. LM 1898/225. (KSF 334). Drikkebæger i slagterlavet. (KSF 336).

Bestik sst. 1812. (KSF 337).

Bæger 1816 i S. Nicolai skyttegilde. FM 3894. (KSF 343). Fig. 21. Skjolde på samme velkomst $1813,1814,1816$. (KSF 342).

Skjolde på slagtervelkomst 1805, 1810, 1812. FM 5591. (KSF 336). Tedåse 1812. FM 6992.

113. CARL FRIEDRICH GEORG WOHLBERG

B.: 15. 12. 1797. (1768-18). G.: Datter af nr. 101. Hus nr. 46 på Storegade. Fo. 1803 og 1835.

Arbejder:

Drikkebager i slagterlavet 1829. (KSF 336).

Skjolde på velkomst i $S$. Johs. skyttegilde $1812,1823,1830,1836$, 1843. (KSF 343).

Hovedvandsæg i FM og LM. Fig. 23.

Teske. FM 12438.

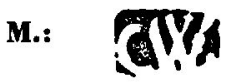

114. JASPER BOYSEN KREBS

B.: 11. 2. 1799. (1770-1808). Søn af ur. 102. Hus nr. 351 i Kompagnigade. Fo. 1803.

1 15. PETER HANSEN

B.: 0. 1800. (1775-). Hus nr. 505 i Augelbogade. Fo. 1803.

116. WILFIELM CHRISTIAN HANSEN

B.: 24. 3. 1801. (1773-1829). S. Nicrolai s.

Arbejder:

Disk u. å. Steinberg/Fl. (KLF 345)

Oblatæske u. å. Sørup/Fl. (KLF 320).

Hovedvandsæg. Louis XVI. FM 10017. Tonder-type.

M.: ver

117. CHRISTIAN LASSEN

B.: 24. 3. 1801. (1776-). Hus nr. 703 i Johamnesgade. Fo. 1803.

Arbejder:

Rep. af alterkande i S. Johs./FI. 1806. (KSF 227).

M.: 2. 
118. CHRISTIAN JUNGSTRÖM

Søger forgæves om tilladelse til at etablere sig 1804. (Fl. St. Acta 373). Fo. 1803. S. Marie s. Skibbroen. Hus nr. 377.

119. HANS FEDDERSEN

B.: 20. 2. 1809. (1779-1826). Søn af Chr. F., Tønder. S. Nicolai s. Arbejder:

Fornyelse af slagtervelkomst 1812. FM 5591. (KSF 335).

2 drikkebægre i slagterlavet 1814. (KSF 336).

2 drikkebægre 1820 og 21 . (Sst).

Skjold på S. Johs. skyttegildes velkomst 1821. (KSF 343).

Hovedvandsæg 1812. FM 8425. Tønder-type.

Platmenage fra slagterlavet. FM 5591.

м.: SARs

120. RIEWERT IVERSEN

B.: 20. 2. 1809. $(1780-1860)$. Søn af nr. 101. Hus nr. 11 i Storegade. Fo. 1835.

Arbejder:

Et par lysestager 1808. Helliggejst/Fl. (KSF 246).

Hovedvandsæg 1834. FM 8412.

Hovedvandsæg. FM 5430.

Skjold på S. Johs. skyttegildes velkomst 1852.

121. ANDREAS STUBBFUS

B.: 3. 3. 1810. S. Marie s. Fmtl. kun svend.

122. JOHANN JOHANNSEN

B.: 24. 2. 1812. S. Nicolai s.

123. JACOB IVERSEN

B.: 20. 2. 1815. (1771-). 1796 g. m. datter af nr. 90. En tid guldsmed i Gråsten. Hus nr. 305 i Storegade. Fo. 1835.

124. H. P. PETERSEN

B.: 20. 2. 1815. S. Nicolai s.

125. ANDREAS FRIDRICH LEHNE

B.: 4. 2. 1816. (1772-). Hus nr. 740 i Johannesgade. Fo. 1835.

Arbejder:

Hovedvandsæg 1816. LM 1924/94. Fig. 23.

M.: AFL (i oval)

126. JOHANN HEINRICH FRIEDRICH SCHMIDT

B.: 27. 2. 1818. S. Nicolai s. 
127. JOHANN CHRISTIAN LASSEN

B.: 21. 2. 1820. S. Nicolai s.

Arbejder:

Hovedvandsæg. FM 8418.

M.: LASSEN (i liggende oval)

128. HANS HINRICH SPRING

B.: 21. 2. 1820. (1794-). Hus nr. 31 i Storegade. Fo. 1835.

129. PETER WILHELM ROSE

B.: 27. 2. 1822 i Haderslev (1797-1841), men svend hos Hans Balzer 1835 . Fo. 1835.

130. JOHAN FRIEDRICH CARSTENS

B.: o. 1825. (1799-). Hus nr. 710 i Johs.gade. Fo. 1835.

131. CHRISTIAN BALZER

B.: 20. 2. 1826. (1797-1883). Son af nr. 112. S. Nicolai s.

Arbejder:

Kalk 1833. Sørup/FI. (KLF 320).

Drikkebæger i slagterlavet 1831. FM 5591. (KSF 336).

Salmebogsbeslag 1828. FM 9850.

132. JENS IVERSEN

B.: 13. 2. 1828. (1801-32). Fra Alborg.

133. FRIEDRICH JESSEN

B.: 13. 12. 1828. (1802-). G. m. datter af nr. 119. Hus nr. 632 i Storegade. Fo. 1835 .

Arbejder:

Sygekalk + disk 1835. Enge/ST. (KKS 97).

Fiskeske. LM 1936/15.

Hovedvandsæg. FM 5645.

\section{M.: IESXSEN}

134. CHRISTIAN HEINRICH HANSEN

B.: 23. 2. 1829. (1800-73). Fra Tønder. Bopal v. Søndertorv. Fo. 1835.

Arbejder:

Sygekalk 1842. Ravsted/Tø. (DK 1595).

Sukkerstrøer 1833. LM 1933/96. Fig. 24.

Spiseske 1846. LM 1924/36.

Iovedvandsæg 1845. FM 5647. 
135. JURGEN WILHELM BADE

B.: 22. 2. 1830. (1779-). Hus nr. 701 i Johannesgade. Fo. 1835. Også i Tonning. St. 757.

136. ANDREAS WOHLBERG

B.: 21. 2. 1831. (1800-). Son af nr. 113. Hus nr. 599 på Søndertorv. Fo. 1835.

Arbejder:

Drikkebæger i slagterlavet 1840 . (KSF 336).

Skjold pí velkomst i S. Johs. skyttegilde 1842. (KSF 343).

Flodeske fra Rödemis 1838. LM 1936/43.

137. HANS JACOB BALZER

B.: 22. 2. 1836. (1805-80). Son af nr. 112. Svend dær 1835. Fo.

Arbejder:

Plodeske. I.M 1937/160.

138. CHRISTIAN FRIEDRICH WOHLBERG

B.: 22. 2. 1836. (1808-). Son af nr. 113. Svend dær 1835. Fo.

139. CARL FRIEDIRICH LEOPOLD DAMM

B.: 20. 2. 1837. (1811-). Bor v. byfængslet 1835. Fo.

Arbejder:

2 spiseskeer 1839 . NM 3798 og $802 / 1920$.

140. JOHAN CHRISTOPHER CHRISTIAN ERICHSEN

13.: 20. 2. 1837. (1809-). Svend hos Chr. H. Hansen 1835. S. Nicolai. Firma med nr. 156. Fo.

141. HANS NICOLAI JONATHAN LASSEN

B.: 2. 3. 1840. (1813-98). Son af nr. 117. Anfores som stifsøn af nr. 130. Laredreng hos Balzer 1835. Fo.

Arbejder:

Kalk + disk 1847. Westerland/ST. (KKS 390).

IRep. af oblataske. Sorup/FI. (KLF 320).

Leverede solvoblattallerken (t) til Ø. Hojst/Tø. 1883. (DK 1578)

M. Reprgersen

I 12. HANS P. HANSEN

B.: 1. 3. 1841. Kaldet "Neusilberarbeiter". S. Nicolai s.

143. JOHANN CARI HABIG

B.: 4. 3. 1844. (1816-e. 1884). G. m søster til nr. 150. S. Nicolai s. 
144. CHIISTIAN E. FEDDERSEN

B.: 6. 2. 1846. (1821-). Anf. som købmand. S. Marie.

145. NICOLAY BALZER

B.: 10. 2. 1847. (1817-e. 91). Søn af nr. 112. Lærling dær 1835. Fo.

146. CHRISTIAN WILHELM A. FEDDERSEN

B.: 31. 10. 1847. (1819-). S. Johs.

147. ANDREAS RIEWERT IVERSEN

B.: 14. 1. 1847. (1822-). S. Marie s.

Arbejder:

Disk fra 1729, nyforgyldt o. 1873. Kappeln/Schl. (KLS 351).

Flødeske med musling. FM 12920.

148. JOHAN HERMAN BEYREIS

B.: 14. 11. 1848. S. Nicolai $s$.

Arbejder:

Bæger i slagterlavet 1860. (KSF 336).

2 nyrokoko spiseskeer. 1876. FM 19298.

149. CARL PETERSEN REU

B.: 25. 8. 1852. (1812-64). Fra Ulstrup i Angel. Svend hos Wohlberg 1835. Fo.

150. JACOB HEINRICH GERWITZ

B.: 7. 7. 1854. (1819-59). S. Marie s.

151. FERDINAND HEINRICH SAUERMANN

B.: 19. 8. 1854. (1824-). Fra Buxtehude. S. Nicolai s.

152. JOHAN FRIEDRICH ROHLFS

B.: 14. 5. 1856. (1821-). Fra Steinberg. S. Nicolai s.

Arbejder:

Spiseskeer. Nyrokoko. 1872. FM 19300.

M.: ROHLFS (i rektangel)

153. CHRISTIAN MORUP

B.: 11. 10. 1856. Fra Randers. S. Nicolai s.

Arbejder:

Spiseskeer.

M.: C. MORUP (i rektangel) 
154. ANDREAS JACOB LUDWIG BRAUTSCH

B.: 25. 11. 1859. (1828-). Fra Augustenborg. En periode guldsmed i Leck. (St. Fl. Acta 373).

Arbejder:

Spiseskeer.

M.: BRAUTSCH (i rektangel)

155. ERNST CHRISTIAN HEINRICH BRUNING

B.: 10. 10. 1863. (1828-). Fra Sønderborg.

Arbejder:

Oblatæske 1911. Branderup/Ha. (DK 856).

Barneske.

M.: Brũning (i rektangel) EB

156. CARL NICOLAI MÜLLER

B.: 21. 9. 1865. (184l $\cdots)$. Fra Tønder. S. Nicolai.

Arbejder:

Spiseske. Nyrokoko. 1872. FM 19299.

M.: C. MULLER (i rektangel)

157. JACOB Ë̈ICHSEN

B.: 15. 11. 1865. (1838-98). Fra Højer. S. Nicolai.

158. PETER CHRISTIAN IVRIEDRICH BRADTBERG

B.: 6. 3. 1866. (1836-). S. Marie s.

Arbejder:

Dobbeltriflet ske 1870. FM 19301.

M.: BRADTBERG (i rektangel)

159. ASMUS CHRISTIAN PETERSEN

B.: 6. 4. 1866. (1833-). Fra Brunsbïllund. Guldsmedesvend.

160. HANS HEINRICH THOMSEN

B.: 15. 5. 1866. (1831-). S. Nicolai s.

Arbejder:

Spiseskeer.

M.: Thomsen (i rektangel)

161. HEINRÏCH MARQUARD ALFRED GROERSEN

B.: 18. 5. 1868. (1831-).

162. CHRISTIAN NICOLAI BALZER

B.: o. 1875. (1850-1925). Søn af nr. 145. Apenraderstr. 8.

163. ADOLPH JOHANNES LUDWIG BEYREIS

(1853-83). Søn af nr. 148. 


\section{EFTERSKRIFT}

Uden støtte fra museumsdirektør, dr. Ellen Redle/sen, Flensborg, og arkivleder, dr. Otto Schütt, Flensborg, havde det været umuligt at tilvejebringe det meget nye materiale denne afhandling rummer. Foruden en ærbødig tak til dem må jeg fremhæve den betydningsfulde hjælp fra redaktør, mag. art., fru Vibeke Michelsen, DANMARKS KIRKEl, Landeskonservator, dr. $H$. Beseler, Landesamt für Denkmalpflege, dr. G. Spies fra Schleswig-Holsteinisches Landesmuseum og kirkeinspektor Rübenach, S. Marie-kirkens kontor i Flensborg. Alle gjorde hvad de kunne for at gore den stillede opgave så let at lose som nu engang muligt.

$S, S$. 


\section{Alfabetisk fortegnelse til Flenshorgs guldsmede 1400-1900}

(Fornavnes initialer først)

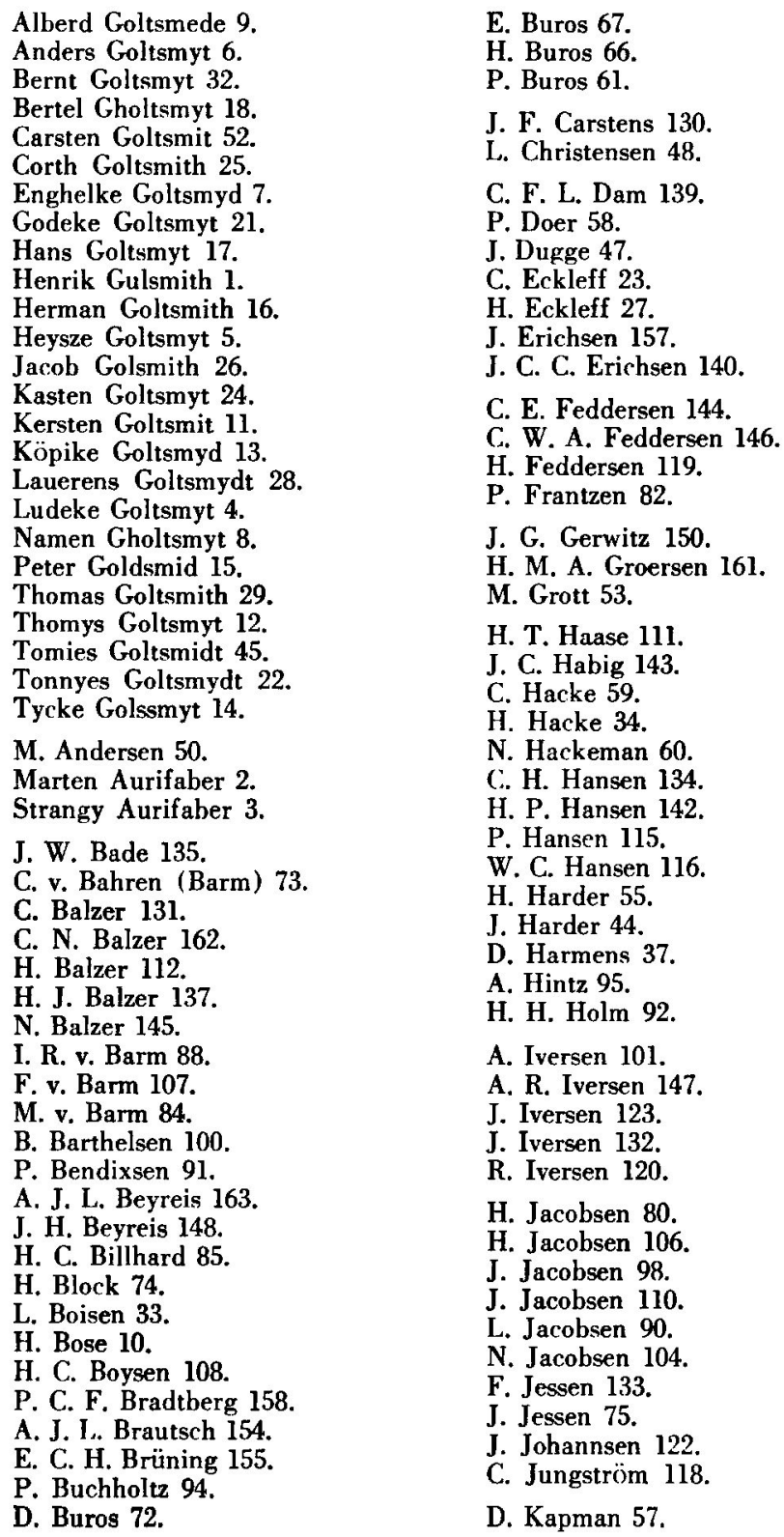


N. Kerstens 40.

H. Kloen 56 .

L. Kloen 43.

A. Kock 51 .

P. Kock 49.

H. Kock 35.

J. B. Krebs 114.

M. Krebs 102.

P. Kull 65.

C. Lassen 117.

H. N. J. Lassen 141.

J. C. Lassen 127.

A. F. Lehne 125.

J. Lembeck 63.

S. Lorentzen 79.

S. Lorentzen 96.

C. Lübecker 77 .

A. Maler 30.

H. Marke 20.

H. Matthiessen 68.

J. Matzen 81.

H. Melchertsen 69.

H. Moreken 19.

C. Mörup 153.

C. N. Müller 156 .

A. Petersen 62.

A. C. Petersen 159.

C. Petersen 149.

C. Petersen 54.

C. Petersen 86.

H. Petersen 38.
H. P. Petersen 124.

A. Petersson 31.

R. Philip 64.

C. Pültzer 70.

P. Rekert 39.

F. C. Richter 103 .

J. Rieber 99.

J. F. Rohlfs 152.

P. W. Rose 129.

F. H. Sauermann 151.

J. H. F. Schmidt 126.

B. Schulz 93.

M. Schweder 71.

P. Spegel 41.

H. H. Spring 128.

D. Steen 78.

J. Steen 76.

J. N. Steen 83.

P. Steen 97.

P. Steen 109.

A. Stubbæus 121.

H. H. Thomsen 160 .

H. Thun 105.

P. Tuxen 42.

J. C. Ulich 87.

B. Wegener 36.

H. Wilhelmsen 89 .

A. Wohlberg 136.

C. F. G. Wohlberg 113 ,

C. F. Wohlberg 138. 